\title{
Update on Edoxaban for the Prevention and Treatment of Thromboembolism: Clinical Applications Based on Current Evidence
}

\author{
Ali Zalpour ${ }^{1}$ and Thein Hlaing $\mathbf{O o}^{2}$ \\ ${ }^{1}$ University of Texas MD Anderson Cancer Center, 1400 Pressler Avenue, Unit 1465, FCT 13.5021, Houston, TX 77030, USA \\ ${ }^{2}$ Section of Thrombosis \& Benign Hematology, The University of Texas MD Anderson Cancer Center, Houston, TX, USA
}

Correspondence should be addressed to Ali Zalpour; azalpour@mdanderson.org

Received 13 April 2015; Revised 18 June 2015; Accepted 21 June 2015

Academic Editor: Elvira Grandone

Copyright (C) 2015 A. Zalpour and T. H. Oo. This is an open access article distributed under the Creative Commons Attribution License, which permits unrestricted use, distribution, and reproduction in any medium, provided the original work is properly cited.

\begin{abstract}
Vitamin K antagonists (VKA) and heparins have been utilized for the prevention and treatment of thromboembolism (arterial and venous) for decades. Targeting and inhibiting specific coagulation factors have led to new discoveries in the pharmacotherapy of thromboembolism management. These targeted anticoagulants are known as direct oral anticoagulants (DOACs). Two pharmacologically distinct classes of targeted agents are dabigatran etexilate (Direct Thrombin Inhibitor (DTI)) and rivaroxaban, apixaban, and edoxaban (direct oral factor Xa inhibitors (OFXaIs)). Emerging evidence from the clinical trials has shown that DOACs are noninferior to VKA or low-molecular-weight heparins in the prevention and treatment of thromboembolism. This review examines the role of edoxaban, a recently approved OFXaI, in the prevention and treatment of thromboembolism based on the available published literature. The management of edoxaban in the perioperative setting, reversibility in bleeding cases, its role in cancer patients, the relevance of drug-drug interactions, patient satisfaction, financial impacts, and patient education will be discussed.
\end{abstract}

\section{Introduction}

Unfractionated heparin (UFH), a highly sulfated naturally occurring glycosaminoglycan, was discovered in Howell's laboratories in the early 1920s. Sweet clover disease or hemorrhagic disease of the cattle in Wisconsin led to the discovery of coumarin. Since then, warfarin has become one of the mostly used antithrombotic agents [1]. Low-molecularweight heparin (LMWH) was also discovered in the late 1970 s and early 1980s as clinicians sought longer acting heparins with a more predicable pharmacokinetic profile. UFH requires frequent monitoring and administration in a hospital setting and carries a risk of heparin-induced thrombocytopenia (HIT). Warfarin demonstrates unpredictable pharmacodynamic $(\mathrm{PD})$ and pharmacokinetic $(\mathrm{PK})$ properties and numerous drug-drug and drug-food interactions and requires frequent international normalized ratio (INR) monitoring. In the past decade, an injectable factor Xa inhibitor, fondaparinux, was introduced. LMWH and fondaparinux exhibit a more predictable $\mathrm{PK}$ and PD profile, but patients are subjected to injections that can be burdensome [2].

Advances in pharmacology and drug design therapy have led to the development and introduction of DOACs such as dabigatran, rivaroxaban, apixaban, and edoxaban [3-5]. DOACs have been approved for the prevention of stroke in nonalular atrial fibrillation (NVAF) and the prevention and treatment of venous thromboembolism (VTE). Numerous trials have shown noninferiority of DOACs compared to standard-of-care (SOC) anticoagulants. DOACs have eased the burden of frequent monitoring and painful injections, curtailed food and drug interactions, reduced cost, and achieved higher degree of patient satisfaction $[6,7]$.

\section{Physiology of Hemostasis and Pharmacology of Edoxaban}

Coagulation cascade is a multistep interaction characterized by the sequential activation of coagulation factor proteins and 


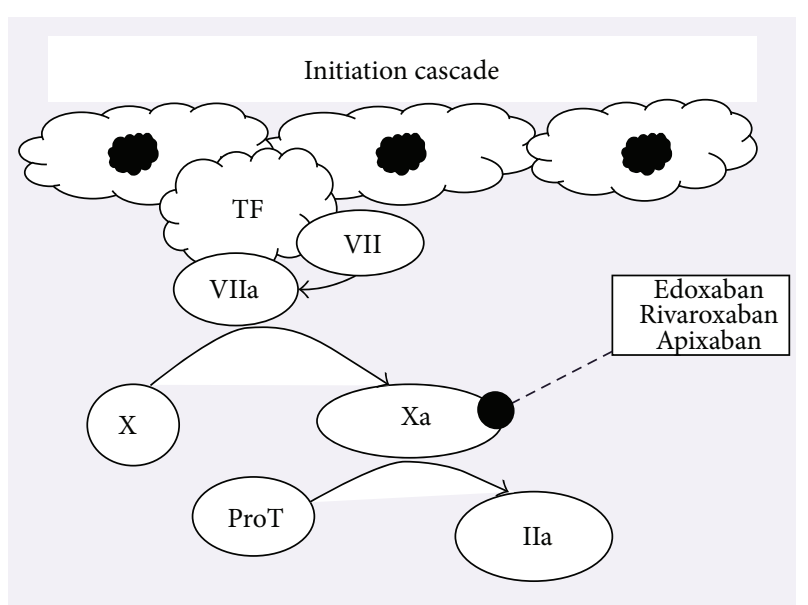

FIgURE 1: Adapted with permission: Zalpour and Oo [8]. Abbreviations: TF, tissue factor; VII, factor VII; VIIa, activated factor VII; X, factor X; Xa, activated factor X; ProT, prothrombin; IIa, thrombin; IX, factor IX; IXa, activated factor IX; Xa, activated factor X; Va, activated factor V; VIIIa, activated factor VIII; vWF, Von Willebrand factor.

their interactions with platelets [9]. Preserving hemostasis is an intricate process following the activation of intrinsic (contact activation) or extrinsic (tissue factor) pathways [10, 11]. The initiation phase of the coagulation involves the generation of tissue factor (TF) which subsequently leads to the activation of factors FVIIa and FXa and the generation of FIIa (thrombin). In the amplification and propagation phases, thrombin activates platelets and, in sequence, factors VIIIa and IXa. Platelet activation induces a surge in thrombin generation leading to the clot formation within the vasculature [12]. The vitamin K antagonist inhibits factors II, VII, XI, and $\mathrm{X}$ and proteins $\mathrm{C}, \mathrm{S}$, and $\mathrm{Z}$ [13]. Heparins inactivate FIIa and FXa via binding their saccharide chain to antithrombin (AT) [14]. FXa is considered a great target for inhibition, as one molecule of FXa can generate approximately 1,000 molecules of thrombin [15]. Edoxaban inhibits thrombin generation by actively inhibiting free and bound FXa in the prothrombinase complex. This inhibition leads to halting of positive feedback loop existing between FXa and FIIa (Figures 1 and 2). The capability of edoxaban to penetrate into the thrombus and rendering free and bound $\mathrm{FXa}$ inactive is proven to be beneficial, for the need for AT-drug complex is diminished [12].

\section{Pharmacodynamics and Pharmacokinetics of Edoxaban}

Edoxaban (molecular weight $838.274 \mathrm{gram} / \mathrm{mol}$ ) exhibits a high affinity (>10,000-fold) to inhibit FXa without the need of binding to antithrombin and has a low affinity for FIIa [16]. Edoxaban is 55\% protein bound and not completely removed by dialysis. The absorption of edoxaban from the gastrointestinal tract is about $60 \%$ and food has minimal effect on systemic exposure of area under the curve (AUC) [17]. Edoxaban reaches a maximum concentration in 1-2 hours and has a low volume of distribution of $\sim 19.9$ liters. In a phase $1 \mathrm{PK}$ study of edoxaban, the $T_{1 / 2}$ was 5.71 to 10.7 hours after a single dose administration ranging from $10 \mathrm{mg}$ to $150 \mathrm{mg}$ and 8.75 to 9.75 hours after multiple doses of edoxaban ranging from $90 \mathrm{mg}$ to $120 \mathrm{mg}$ daily [18]. The mean elimination half-life of edoxaban is estimated in the range of 10-14 hours and reaches a steady state concentration in 72 hours. Edoxaban is metabolized via hydrolysis with minimal enzymatic pathways of liver (CYP metabolism is less than $4 \%$ ). Human carboxylesterase 1 (hCE-1) forms M4, a major metabolite of edoxaban, which is pharmacologically active. M4 reaches less than $10 \%$ of the exposure of the parent compound in healthy subjects. Exposure to the other metabolites of edoxaban is less than 5\%. Edoxaban elimination is 50\% via renal route and $50 \%$ via biliary and intestinal route [19]. Age has no direct effect on the PK of edoxaban; however, in patients with body weight less than 60 kilograms, there is an increase in exposure [20]. In a PK simulation study of 278 patients from phase 1 trials, the bioavailability $(F)$ was estimated to be $67.2 \%$ in a dose ranging from 10 to $30 \mathrm{mg}$. Female patients exhibited $13.1 \%$ lower clearance $(\mathrm{CL})$ than males. $\mathrm{AUC}_{\infty}$ in females was higher than that in males as the dose of edoxaban increased from $10 \mathrm{mg}$ to $180 \mathrm{mg}$; for example, in the edoxaban $90 \mathrm{mg}, \mathrm{AUC}_{\infty}$ is $3,385(\mathrm{ng} * \mathrm{~h} / \mathrm{mL})$ in male patients and $3,893(\mathrm{ng} * \mathrm{~h} / \mathrm{mL})$ in female patients, respectively. The clinical significance of these findings has not been validated in clinical trials (Table 1) [21].

3.1. Pharmacodynamics and Pharmacokinetics of Edoxaban in Patients with Liver Dysfunction. The presence of encephalopathy or ascites (clinical parameters) along with serum albumin, serum bilirubin, and prothrombin time (laboratory parameters) collectively classifies patients into three distinct groups of liver diseases: Child-Pugh A (mild), ChildPugh B (moderate), and Child-Pugh C (severe). Patients with Child-Pugh $\mathrm{C}$ class are typically excluded from the clinical trials involving anticoagulation due to excess bleeding risk [39]. In a hepatic impairment study (Child-Pugh A, $n=$ 8; Child-Pugh $\mathrm{B}, n=8$ ) matched for healthy patients ( $n=16)$, after the administration of single oral dose of edoxaban $15 \mathrm{mg}$, compared to healthy subjects, the $\mathrm{AUC}_{\infty}$ decreased by $4.2 \%$ in subjects with Child-Pugh $\mathrm{A}$ and $4.8 \%$ in subjects with Child-Pugh $\mathrm{B}$. The peak serum concentration $\left(C_{\max }\right)$ decreased by $10 \%$ and $32 \%$ in patients with ChildPugh A and Child-Pugh B, respectively [40]. Currently, no PK data exists for edoxaban use in patients with Child-Pugh $\mathrm{C}$ and the use of edoxaban in patients with moderate or severe hepatic impairment (Child-Pugh B and Child-Pugh C) is not recommended as these patients may have intrinsic coagulation abnormalities [17].

\subsection{Pharmacodynamics and Pharmacokinetics of Edoxaban} in Patients with Renal Dysfunction. Patients with end stage renal disease (ESRD) are typically excluded from the edoxaban clinical trials, because of increased bleeding risk. For patients with ESRD who may require anticoagulation, VKA and UFH are the anticoagulants of choice [41]. All OFXaIs have some degree of renal elimination: apixaban $27 \%$, 


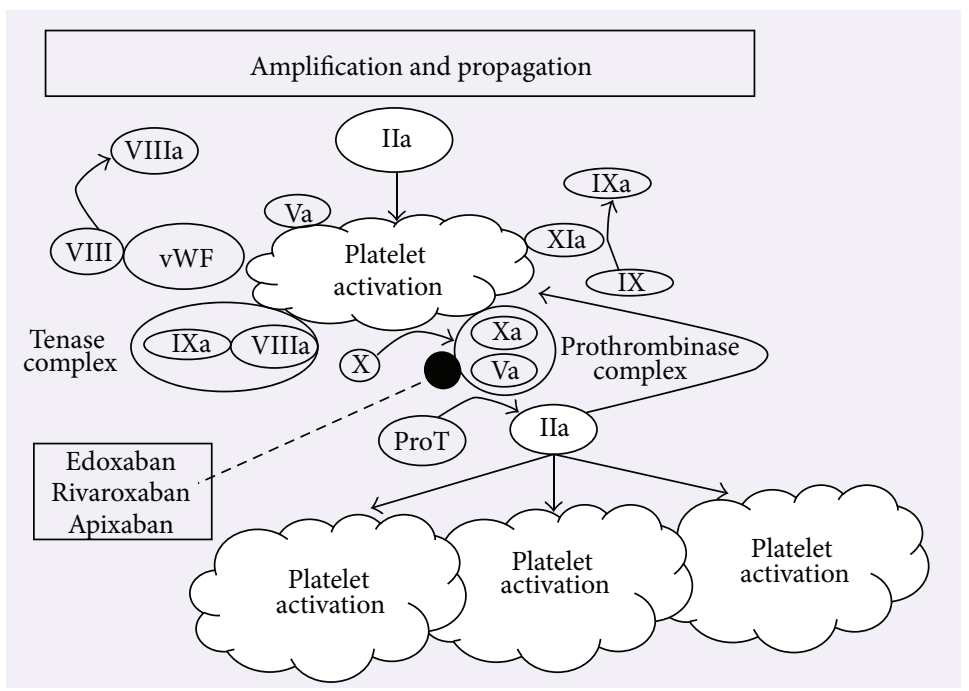

FIgURE 2: Adapted with permission: Zalpour and Oo [8]. Abbreviations: TF, tissue factor; VII, factor VII; VIIa, activated factor VII; X, factor $\mathrm{X}$; Xa, activated factor X; ProT, prothrombin; IIa, thrombin; IX, factor IX; IXa, activated factor IX; Xa activated factor X; Va, activated factor V; VIIIa, activated factor VIII; vWF, Von Willebrand factor.

TABLE 1: Edoxaban pharmacodynamics and pharmacokinetics [16-21].

\begin{tabular}{ll}
\hline Drug/mechanism of action & Edoxaban/direct oral factor Xa inhibitor (FXa-I) without antithrombin III \\
\hline & $\begin{array}{l}\text { (1) Treatment of nonvalvular atrial fibrillation (NVAF) } \\
\text { (i) } 60 \mathrm{mg} \text { orally daily for CrCl greater than } 50 \text { to less than or equal to } 95 \mathrm{~mL} / \mathrm{min}\end{array}$ \\
Indication and dosing guidelines & $\begin{array}{l}\text { (ii) } 30 \mathrm{mg} \text { orally daily for } \mathrm{CrCl} 15-50 \mathrm{~mL} / \mathrm{min} \\
\text { (2) Treatment of venous thromboembolism (VTE) }\end{array}$ \\
& $\begin{array}{l}\text { (i) } 60 \mathrm{mg} \text { orally daily } \\
\text { (ii) } 30 \mathrm{mg} \text { orally daily if CrCl is } 15-50 \mathrm{~mL} / \mathrm{min} \text { or body weight is less than } 60 \mathrm{Kg} \text { or }\end{array}$ \\
patient is on P-gp inhibitor
\end{tabular}

Bioavailability, F; creatinine clearance, cytochrome P450 3A4 (CYP3A4/5), CrCl; half-life, $T_{1 / 2}$; P-glycoprotein/ABCG2, P-gp/ABCG2; volume of distribution, $\mathrm{Vd}$, time to reach maximum concentration in hours $(\mathrm{h}), T_{\max }$.

rivaroxaban $33 \%$, and edoxaban $50 \%$. OFXaIs are excluded in clinical trials enrolling patients with $\mathrm{CrCl}<25-30 \mathrm{~mL} / \mathrm{min}$ [42]. The safety and PK of edoxaban $(15 \mathrm{mg}, 30 \mathrm{mg}$, and $60 \mathrm{mg}$ ) daily for 12 weeks in patients with normal or mild renal insufficiency $(\mathrm{CrCl} \geq 50 \mathrm{~mL} / \mathrm{min})$ and severe renal insufficiency ( $\mathrm{CrCl} \geq 15$ to $<30 \mathrm{~mL} / \mathrm{min}$ ) in 92 patients have been evaluated. Patients on hemodialysis or at high risk for bleeding were excluded. The dose of edoxaban was decreased by $50 \%$ in patients with normal or mild renal insufficiency who weigh less than $60 \mathrm{~kg}$ or who are on verapamil or quinidine. The bleeding complication rates in patients with severe renal impairment (edoxaban $15 \mathrm{mg}$ group) and normal or mild renal insufficiency (edoxaban $30 \mathrm{mg}$ or edoxaban $60 \mathrm{mg}$ group) were $20 \%, 23.8 \%$, and $22.7 \%$, respectively. This study showed that edoxaban $15 \mathrm{mg}$ might be appropriate for patients with severe renal insufficiency [43]. 
In a PK study of 10 patients with ESRD on dialysis, patients received a single dose of edoxaban $15 \mathrm{mg}$ in 2 different schemes: on-dialysis days, 2 hours before, and off-dialysis days between hemodialysis sessions. Patients with history of bleeding, major trauma, or major surgical procedure, peptic ulcer, or gastrointestinal bleeding within the past 6 months or those who use any drugs that are strong inhibitors or inducers of CYP3A 4 or P-gp within the past 4 weeks were excluded. $T_{1 / 2}$ was $10.6 \pm 3.13$ hours in on-dialysis group and $10.4 \pm$ 2.72 in off-dialysis group. $T_{\max }$ on-dialysis and off-dialysis was 2.3 and 2.0 hours accordingly. The $C_{\max }$ was $53.3 \pm 15.14$ nanograms/milliliter $(\mathrm{ng} / \mathrm{mL})$ in on-dialysis group and $56.3 \pm$ $23.25 \mathrm{ng} / \mathrm{mL}$ in off-dialysis group. The $\mathrm{AUC}_{\infty}(\mathrm{ng} * \mathrm{~L} / \mathrm{hr})$ was $676.2 \pm 220.86$ in on-dialysis group versus $691.7 \pm 149.84$ in off-dialysis group. Clearance measured in (CL/h) was $24.7 \pm$ 7.07 and $22.5 \pm 4.50$ in on-dialysis and in off-dialysis groups, respectively. These results showed that hemodialysis did not alter the PK of edoxaban. Mean percent of edoxaban protein binding remained $\sim 60 \%$ in on- and off-dialysis groups. The effect of dialysis on M-4 (active metabolite of edoxaban) on $C_{\max }$ in on-dialysis and off-dialysis was $9.8 \pm 7.05 \mathrm{ng} / \mathrm{mL}$ and $10.2 \pm 4.98 \mathrm{ng} / \mathrm{mL}$, respectively. The $T_{\max }$ was prolonged in off-dialysis group to 4 hours versus 2.1 hours in ondialysis group and the $\mathrm{AUC}_{\infty}$ was lower in off-dialysis group versus on-dialysis group, $151.9 \pm 101.843(\mathrm{ng} * \mathrm{~L} / \mathrm{hr})$ versus $193.3 \pm 255.48(\mathrm{ng} * \mathrm{~L} / \mathrm{hr})$. The $T_{1 / 2}$ was prolonged at 8.05 to 17.95 hours in on-dialysis group versus 7.52 to 15.08 hours in off-dialysis group. There was no bleeding, death, or any serious adverse reactions. This study showed that dialysis has no effect on the removal of edoxaban [44]. Currently, there are no clinical trials comparing different does of edoxaban in patients with renal insufficiency; however, a recent metaregression analysis was undertaken to examine the safety and efficacy of DOACs versus warfarin in patients with various degrees of renal function. The hazard ratio (HR) of bleeding in patients with moderate renal impairment ( $\mathrm{CrCl} 25-49 \mathrm{~mL} / \mathrm{min})$, mild renal impairment $(\mathrm{CrCl} \mathrm{50-}$ $79 \mathrm{~mL} / \mathrm{min})$, and nonrenal impairment $(\mathrm{CrCl}>80 \mathrm{~mL} / \mathrm{min})$ has been estimated for edoxaban $30 \mathrm{mg}$ versus warfarin as HR: 0.31 (95\% Confidence Interval (CI): 0.23-0.42) in moderate renal impairment, not reported in mild renal impairment, and HR: 0.55 (95\% CI: 0.46-0.65) for nonrenal impairment patients. Comparing edoxaban $60 \mathrm{mg}$ against warfarin resulted in HR: 0.63 (95\% CI: 0.50-0.81) in moderate renal impairment, not reported in mild renal impairment, and HR: 0.88 (95\% CI: 0.76-1.03) in nonrenal impairment. In patients with $\mathrm{CrCl} 25-49 \mathrm{~mL} / \mathrm{min}$, indirect comparison between DOACs showed less major bleeding with apixaban compared to dabigatran, rivaroxaban, and edoxaban $60 \mathrm{mg}$, but not edoxaban $30 \mathrm{mg}$. Edoxaban $30 \mathrm{mg}$ demonstrated less major bleeding in all comparisons to other DOACs. The HR of major bleeding for edoxaban $30 \mathrm{mg}$ versus edoxaban $60 \mathrm{mg}$ was estimated as 0.49 (95\% CI: $0.33-0.72)$. In patients with $\mathrm{CrCl} 50-79 \mathrm{~mL} / \mathrm{min}$, edoxaban $30 \mathrm{mg}$ offered a lower major bleeding profile compared to other DOACs. Edoxaban $30 \mathrm{mg}$ versus edoxaban $60 \mathrm{mg}$ showed $\mathrm{HR}$ of bleeding as $0.63(95 \%$ CI: 0.50-0.79) [45]. The PK differences such as $T_{\max }, T_{1 / 2}$, $F$, and various degrees of renal elimination could potentially confound the results of this metaregression. A recent multicenter, open-label, 3-parallel-group, phase 3 study in Japanese patients undergoing lower limb replacement has evaluated the safety of edoxaban administered for 11 to 14 days. Patients with mild renal insufficiency or $\mathrm{CrCl} \geq 50$ to $\leq 80 \mathrm{~mL} / \mathrm{min}$ received oral edoxaban $30 \mathrm{mg}$ once daily. Patients with severe renal insufficiency or $\mathrm{CrCl}>20$ to < $30 \mathrm{~mL} / \mathrm{min}$ were randomized to receive edoxaban $15 \mathrm{mg}$ once daily or fondaparinux $1.5 \mathrm{mg}$ daily. Patients with severe renal insufficiency or $\mathrm{CrCl} \geq 15$ to $\leq 20 \mathrm{~mL} / \mathrm{min}$ received edoxaban $15 \mathrm{mg}$ daily. Edoxaban was given 12-24 hours after surgery. Patients undergoing hemodialysis, high risk of bleeding, risk of thromboembolism, hepatic dysfunction, spinal anesthesia, inability to take oral medication, and abnormal bleeding after surgery were excluded. There was no major bleeding in any groups; and clinically relevant bleeding occurred at a rate of $6.7 \%$ in mild renal insufficiency $(\mathrm{CrCl} \geq 50$ to $\leq 80 \mathrm{~mL} / \mathrm{min}$ on edoxaban $30 \mathrm{mg}$ ), $3.4 \%$ in severe renal insufficiency ( $\mathrm{CrCl} \geq 15$ to $<30 \mathrm{~mL} / \mathrm{min}$ on edoxaban $15 \mathrm{mg}$ ), $0 \%$ in patients in severe renal insufficiency on edoxaban $15 \mathrm{mg}, 4.5 \%$ in severe renal insufficiency $(\mathrm{CrCl} \geq 20$ to $\leq 30 \mathrm{~mL} / \mathrm{min}$ on edoxaban $15 \mathrm{mg}$ ), and $5 \%$ in severe renal insufficiency ( $\mathrm{CrCl} \geq 20$ to $<30 \mathrm{~mL} / \mathrm{min}$ on fondaparinux $1.5 \mathrm{mg}$ ). There was no VTE reported in any treatment groups. This study demonstrated that edoxaban $15 \mathrm{mg}$ is safe in patients with severe renal impairment [46]. The limited number of patients in a subpopulation of Asian patients makes the applicability of data restrictive. The manufacturer recommends dose reduction by $50 \%$ in patients with $\mathrm{CrCl} 15-50 \mathrm{~mL} / \mathrm{min}$ [17].

\section{Edoxaban in Venous Thromboembolism (VTE) Trials}

4.1. Primary Thromboprophylaxis after Knee Surgery. The incidence of $42 \%-57 \%$ for deep vein thrombosis (DVT) on screening, and $0.1 \%-2.0 \%$ for pulmonary embolism (PE), without the use of pharmacologic prophylaxis within 2 weeks in patients undergoing total hip arthroplasty (THA) has been described. In total knee arthroplasty (TKA) setting, incidence of DVT climbs to $41 \%-85 \%$ and prevalence of $\mathrm{PE}$ could be as high as $0.1 \%-1.7 \%$. In hip fracture surgery (HFS), the incidence of DVT is estimated at $40 \%-60 \%$ and prevalence for $\mathrm{PE}$ at $0.3 \%-7.5 \%[47,48]$. In patients undergoing major orthopedic surgery (TKA or THA), the American College of Chest Physicians (ACCP) recommends utilizing one of the following pharmacological antithrombotics rather than no antithrombotic prophylaxis: LMWH, fondaparinux, dabigatran, apixaban, rivaroxaban, low-dose unfractionated heparin (LDUFH), adjusted-dose VKA, aspirin, or an intermittent pneumatic compression device (IPCD) for a minimum of 10 to 14 days. For HFS, the ACCP guidelines do not recommend utilizing DOACs for thromboprophylaxis. These guidelines suggest the use of LMWH in preference to the other agents and adding an IPCD during the hospital stay and suggest extending thromboprophylaxis for up to 35 days. In patients who decline injections, guidelines recommend using apixaban or dabigatran [49]. In the setting of TKA, a dose ranging study of edoxaban ( $5 \mathrm{mg}, 15 \mathrm{mg}, 30 \mathrm{mg}$, and $60 \mathrm{mg}$ ) once daily 
(first dose 6-24 hours after surgery) versus placebo in 523 patients has been conducted in a randomized, double-blind, placebo-controlled fashion for 11-14 days. Importantly, patients at high risk for bleeding, that is, history of intracranial bleeding, gastrointestinal bleeding, intraocular bleeding, peptic ulcer disease, elevated prothrombin time (PT), or activated partial thromboplastin time (aPTT) above the upper normal limit (UNL), hemoglobin $(\mathrm{Hgb})<9 \mathrm{~g} / \mathrm{dL}$ or platelets of $<100,000 / \mathrm{mm}^{3}$, systolic blood pressure (SBP) $>160 \mathrm{mmHg}$ or diastolic blood pressure (DBP) $>100 \mathrm{mmHg}$, inherited coagulation abnormality, history of VTE, myocardial infarction, cerebral infarction, or transient ischemic attack (TIA), body weight $<40 \mathrm{~kg}$, concurrent antiplatelet therapy, pregnancy, and clinically significant hepatic dysfunction, that is, liver enzymes (LFTs) or total bilirubin above 1.5 times upper limit of normal (UNL). The incidence of thromboembolic complications (DVT, PE) or primary endpoint in placebo and edoxaban ( $5 \mathrm{mg}, 15 \mathrm{mg}, 30 \mathrm{mg}, 60 \mathrm{mg}$ ) was $48.3 \%$, 29.5\%, $26.1 \%, 12.5 \%$, and $9.1 \%$, respectively, $P<0.001$, for all comparisons (placebo versus edoxaban). No major bleeding was observed in placebo and in only 1/106 (0.9\%) in edoxaban $60 \mathrm{mg}$ daily, all statistically nonsignificant. The clinically relevant nonmajor bleeding (CRNM) was 3.9\% in placebo, $1.9 \%$ in edoxaban $5 \mathrm{mg}, 3.8 \%$ in edoxaban $15 \mathrm{mg}$, 3.9\% in edoxaban $30 \mathrm{mg}$, and $3.8 \%$ in edoxaban $60 \mathrm{mg}$ groups accordingly. Notably, the incidence of treatment-related bleeding increased with higher doses of edoxaban $(P=0.004)$. There were no elevations in liver enzymes associated with edoxaban therapy. Additionally, single doses of edoxaban $(5-60 \mathrm{mg})$ resulted in dose-dependent increases in anti-FXa activity, demonstrating target-specific effect versus placebo [50]. Nonpharmacological thromboprophylaxis (21-28\% IPC and $72 \%$ elastic stockings) was used in addition to edoxaban, but no stratified analysis was provided on their effect on the outcomes. The effect of anti-FXa on clinical outcomes was not measured. This study confirmed the higher degree of bleeding with higher doses of edoxaban. A retrospective study of 300 patients undergoing TKA analyzed the safety and efficacy of edoxaban $15 \mathrm{mg}$ daily for the prevention of DVT administered for 14 days. This study compared edoxaban $15 \mathrm{mg}$ daily versus enoxaparin $20 \mathrm{mg}$ twice daily versus fondaparinux $1.5 \mathrm{mg}$ daily. The incidence of total DVT in enoxaparin, fondaparinux, and edoxaban was $28 \%, 28 \%$, and $22 \%$ accordingly, not statistically significant, and no PE was noted. Hemoglobin levels were lower in patients with edoxaban than in patients with enoxaparin and fondaparinux on postoperative days; however, the difference was not statistically significant. Finally, the incidence of hepatic dysfunction was lower in patients with edoxaban than in patients with enoxaparin and fondaparinux [51]. Applying the results of a retrospective study into clinical practice poses many challenges. This study provided very limited information of patient's baseline characteristics, that is, renal function, concomitant use of IPCS, and comorbidities. Utilization of different doses of fondaparinux $(1.5 \mathrm{mg})$ and enoxaparin ( $20 \mathrm{mg}$ twice daily) is questionable in western countries as such doses are not recommended. Finally, no conclusion can be drawn for the efficacy and safety of edoxaban $30 \mathrm{mg}$ daily. In a randomized double-blind, double-dummy trial of TKA patients $(n=716)$, the safety and efficacy of edoxaban $30 \mathrm{mg}$ (first dose given 6-24 hours after surgery) were compared to enoxaparin $20 \mathrm{mg}$ twice daily (first dose 6-24 hour after surgery) for 11-14 days. Patients at high risk for bleeding, high risk for VTE, body weight $<40 \mathrm{Kg}, \mathrm{CrCl}$ $<30 \mathrm{~mL} / \mathrm{min}$, hepatic dysfunction, concomitant antiplatelet, or thrombolytic agents or pregnant patients were excluded. Patients in whom epidural catheter could not be removed by 2 hours prior to the initiation of study were not enrolled as well. The primary efficacy outcome (thromboembolic events) occurred in $7.4 \%$ and $13.9 \%$ patients in the edoxaban and enoxaparin groups, respectively (relative risk reduction $=$ $46.8 \%)$, demonstrating noninferiority $(P<0.001)$ and superiority $(P=0.010)$ of edoxaban over enoxaparin. In the edoxaban and enoxaparin groups, the major bleeding (primary safety outcome) occurred in $1.1 \%$ versus $0.3 \%$ of patients $(P=0.373)$. Major or CRNM bleeding occurred in $6.2 \%$ versus $3.7 \%$ patients $(P=0.129)$, accordingly. There was no report of drug-induced liver injury. It is important to note that in each group approximately $22 \%$ were permitted to use IPCD and $62 \%$ elastic stockings as nonpharmacological prophylaxis measures [32]. Evidence has shown that addition of IPCD to pharmacological methods further decreased the incidence of VTE in orthopedic surgical patients; however, no analysis was conducted to examine the effect of covariates such as use of IPCD. Together, all of edoxaban data in TKA trials may not be applicable to patients in western countries as weight-based dosing of pharmacological thromboprophylaxis and methods of diagnosis may differ.

4.2. Primary Thromboprophylaxis after Hip Surgery. Edoxaban has been studied in total hip replacement (THR) trial for prevention of VTE. A randomized double-blind dose response of edoxaban on 903 patients undergoing THR has been conducted. In this trial, THR patients were randomized to edoxaban ( $15 \mathrm{mg}, 30 \mathrm{mg}, 60 \mathrm{mg}$, and $90 \mathrm{mg}$ ) versus dalteparin (2,500 units initially then 5,000 units) daily thereafter for 7 days. Patients were excluded if they have known or suspected bleeding or coagulation disorder, hemorrhagic stroke, nonhemorrhagic stroke within the past three months, intraocular hemorrhage, intracranial malignancy, gastrointestinal bleeding, or documented peptic ulcer within the past three months, if they are expected to receive epidural catheter, if they have received spinal or epidural anesthesia with traumatic tap, if they have abnormal PT and aPTT time, positive serology for hepatitis $\mathrm{A}, \mathrm{B}$, and $\mathrm{C}$, known drug or alcohol dependence within the past 12 months, estimated survival of less than 12 months, liver function tests greater than 1.5 times UNL, systolic and diastolic blood pressure > $180 / 110 \mathrm{mmHg}, \mathrm{Hgb}<9 \mathrm{~g} / \mathrm{dL}$, platelet count $<100,000 / \mathrm{mm}^{3}$, if they receive aspirin $>100 \mathrm{mg}$ per day or required concomitant clopidogrel or dipyridamole or nonsteroidal antiinflammatory drugs, and if they received therapeutic dose of VKA or fibrinolytics within the past 10 days. Primary efficacy result, incidence of venographically proven VTE, was reported as $43.5 \%$ (dalteparin), $28.2 \%$ ((edoxaban $15 \mathrm{mg}$ ) versus dalteparin $P=0.005), 21.2 \%$ ((edoxaban $30 \mathrm{mg}$ ) versus 
dalteparin; $P<0.001), 15.2 \%$ ((edoxaban $60 \mathrm{mg}$ ) versus dalteparin; $P<0.001)$, and $10.6 \%$ ((edoxaban $90 \mathrm{mg}$ ) versus dalteparin; $P<0.001)$. Primary safety results, incidence of all bleeding, were reported as $0.6 \%$ (dalteparin), $2.1 \%$ (edoxaban $15 \mathrm{mg}$ versus dalteparin; $P=0.250$ ), $1.8 \%$ (edoxaban $30 \mathrm{mg}$ versus dalteparin; $P=0.122$ ), $4.9 \%$ (edoxaban $60 \mathrm{mg}$ versus dalteparin), and $4.0 \%$ (edoxaban $90 \mathrm{mg}$ versus dalteparin). There was no report of edoxaban induced liver injury. This study showed that edoxaban was effective in reduction of VTE in patients undergoing THR. This study was conducted in a patient population that had a different population PK than patients in North America, and generalizability is limited. No information was provided on the addition of nonpharmacological thromboprophylaxis [33]. A population PK based study of 1,795 patients enrolled in 10 phase 1 studies of edoxaban has been published for patients undergoing THR. Range of plasma concentration of edoxaban (15 mg, $30 \mathrm{mg}, 60 \mathrm{mg}$, and $90 \mathrm{mg}$ ) was reported as $C_{\max , \mathrm{ss}}(200-$ $300 \mathrm{ng} / \mathrm{mL}), \mathrm{AUC}_{\mathrm{ss}}(2000-3000 \mathrm{ng} * \mathrm{~h} / \mathrm{mL})$, and $C_{\text {min,ss }}(20-$ $50 \mathrm{ng} / \mathrm{mL}$ ) and there was a significant predictor of decreasing incidence of VTE in patients undergoing THR: $P<0.005$ for all variables; and no relationship was identified between edoxaban exposure and bleeding [34]. The applicability of these pharmacometric analyses might be to guide the future clinical trials in dosing and monitoring edoxaban in patients undergoing orthopedic surgery. Edoxaban 15 or $30 \mathrm{mg}$ daily versus enoxaparin $20 \mathrm{mg}$ twice daily has been studied for the prevention of VTE in patients undergoing THA in a randomized, active controlled, double-blind, phase II trial of 264 patients. Patients who required revision of THA and had history of intracranial bleeding, history of intraocular bleeding, intracranial tumor, gastrointestinal bleeding or peptic ulcer disease within the past 90 days, or history of symptomatic VTE, patients weighing $<40 \mathrm{~kg}$ and using antithrombotics, $\mathrm{CrCl}<30 \mathrm{~mL} / \mathrm{min}$, and patients with evidence of hepatic dysfunction (LFTs $>2$ times UNL and total bilirubin $>$ 1.5 times UNL) were excluded. Edoxaban was started 6-24 hours after surgery and enoxaparin 24-36 hours after surgery for 11-14 days at which patients underwent venography. The primary endpoint (composite of asymptomatic VTE or symptomatic DVT) occurred in $3.8 \%$ of edoxaban $15 \mathrm{mg}$, $2.8 \%$ in edoxaban $30 \mathrm{mg}$ group (incidence difference of $1.1 \%$ ), and $4.1 \%$ in enoxaparin group. The incidence difference was $-0.2 \%$ and $-1.3 \%$ in edoxaban $15 \mathrm{mg}$ and $30 \mathrm{mg}$ versus enoxaparin, respectively $(P=1.000)$. There were no VTErelated deaths. The incidence of overall bleeding was $18 \%$ in edoxaban $15 \mathrm{mg}, 21.2 \%$ in edoxaban $30 \mathrm{mg}$, and $21.8 \%$ in enoxaparin groups $(P=1.000)$. This study demonstrated that edoxaban once daily showed similar efficacy while maintaining safety as enoxaparin for the prevention of VTE after THA. Approximately $50 \%$ of patients were allowed to have IPCD therapy for sole foot, $40 \%$ IPCD for lower legs and thigh, and $80 \%$ for elastic stockings [52]. The dose of enoxaparin for prophylaxis was different than the dose recommended in the western countries; however, enoxaparin $20 \mathrm{mg}$ twice daily might be appropriate for smaller frame patients. Currently, there are no large scale trials in America and Europe to compare the different doses of edoxaban and enoxaparin. Edoxaban $30 \mathrm{mg}$ daily versus enoxaparin $20 \mathrm{mg}$ twice daily has also been studied for the prevention of VTE in patients undergoing THA in a randomized, double-blind, double-dummy, noninferiority phase III trial involving 610 patients. Edoxaban was started 6-24 hours after surgery and enoxaparin was initiated 24-36 hours after surgery for 11 to 14 days. VTE events occurred in $6.9 \%$ of enoxaparin group and $2.4 \%$ of edoxaban group $(P<0.001$ for noninferiority). No symptomatic DVT or PE was noted in both treatment groups. The incidence of major and CRNM bleeding events was $3.7 \%$ versus $2.6 \%$ in the enoxaparin and edoxaban groups, respectively $(P=0.475)$. The major bleeding rates were $2.0 \%$ versus $0.7 \%$ in the enoxaparin and edoxaban groups, respectively. This study was presented as an abstract and the full paper has not been published yet [35].

\subsection{Primary Thromboprophylaxis after Hip Fracture Surgery} (HFS). To date, one multicenter, open-label, active comparator, phase 3 trial of 92 patients has compared edoxaban $30 \mathrm{mg}$ to enoxaparin $20 \mathrm{mg}$ twice daily for VTE prevention after HFS in Japanese patients for 11-14 days. First dose of edoxaban was given 6-24 hours and enoxaparin 24-36 hours after surgery. Patients were excluded if they were at increased risk of bleeding (e.g., history of intracranial bleeding and recent gastrointestinal bleeding) and patients with prior VTE, recent myocardial infarction, cerebral infarction, transient ischemic attack, body weight $<40 \mathrm{Kg}$, use of concomitant antithrombotics, $\mathrm{CrCl}<30 \mathrm{~mL} / \mathrm{min}$, evidence of hepatic impairment, or abnormal bleeding at the site of anesthesia were also excluded. The primary endpoint of major or CRNM bleeding occurred in 3.4\% (95\% CI: 0.9-11.5) of edoxaban and $6.9 \%$ (95\% CI: 1.9-22.0) of enoxaparin, for absolute difference of $-3.5 \%$ (95\% CI: $-18.8-6.0)$. The secondary endpoint of composite VTE occurred in $6.5 \%$ of edoxaban (95\% CI: $2.2-17.5$ ) and $3.7 \%$ of enoxaparin (95\% CI: $0.7-$ 18.3 ), with absolute difference of $2.8 \%$ (95\% CI: $-12.4-$ 14.2). There were no major adverse events such as death or liver toxicity related to treatment. This study confirmed the efficacy and safety of edoxaban for VTE prevention in highrisk postorthopedic surgical patients [36]. Patient eligibility and recruitment variations along with dosing differences for VTE prevention might impede the generalizability of these findings. Edoxaban is not indicated for the prevention of VTE postorthopedic surgery [17].

\subsection{Primary Thromboprophylaxis in Acutely Ill Medical} Patients. Hospitalized patients admitted for acute medical illnesses such as infection, advanced age, congestive heart failure, acute exacerbation of chronic obstructive lung disease, acute rheumatological disease, immobilization, cancer, respiratory failure, and prior history of thromboembolism are at risk for VTE [53]. Studies have shown the incidence of VTE in acutely ill hospitalized medical patients varies from $5 \%$ to $15 \%$ and this risk could be reduced by $50 \%$ to $75 \%$ with appropriate pharmacological thromboprophylaxis [54-56]. The International Medical Prevention Registry on Venous Thromboembolism (IMPROVE) registry $(n=15$, 156) showed suboptimal VTE prophylaxis rates, less than 
$50 \%$ [57]. The ACCP recommends pharmacological thromboprophylaxis with LMWH, LDUFH, or fondaparinux for acutely ill hospitalized medical patients at increased risk of thrombosis [58]. Currently, there are no recommendations for thromboprophylaxis with OFXaIs in medically ill hospitalized patients. Although data exists for apixaban and rivaroxaban thromboprophylaxis in this setting, to date, no published data exists for edoxaban prophylaxis in acutely ill medical patients $[59,60]$. Generalizability of these data to edoxaban is not clinically advisable, for there are clear PK differences among OFXIs such as protein binding, renal clearance, hepatobiliary elimination, and prophylaxis dosing differences. Edoxaban is not indicated for the prevention of VTE in acutely ill hospitalized patients.

4.5. Initial Treatment of VTE. The overall annual incidence of VTE (DVT and PE) is estimated between 1 and 2 per 1000 of population or between 300,000 and 600,000 cases per year with average treatment cost of $\$ 7594$ to $\$ 16,664$ per case and 10 to $30 \%$ of all patients suffer mortality [61]. The ACCP recommendation for the VTE treatment consists of administration of either UFH or LMWH or fondaparinux for a minimum of 3 months for the first VTE; selected patients may be transitioned to warfarin [62]. OFXaIs have been studied for the initial treatment of acute VTE in several large randomized, noninferiority trials. Rivaroxaban and apixaban are considered noninferior to the standardof-care VTE treatment in the general population [63-65]. The Hokusai-VTE investigated the role of edoxaban versus warfarin for the treatment of symptomatic VTE (DVT and $\mathrm{PE}$ ) in a randomized, double-blind, double-dummy, noninferiority design trial. All patients were initially treated with heparins (UFH or enoxaparin) for a minimum of 5 days followed by warfarin (target INR 2-3) or edoxaban $60 \mathrm{mg}$ daily unless the body weight was $<60 \mathrm{Kg}$ or $\mathrm{CrCl}$ was $30-$ $50 \mathrm{~mL} / \mathrm{min}$ or were on potent P-glycoprotein inhibitor, in which cases edoxaban $30 \mathrm{mg}$ daily was given for a minimum of 3 months in all patients and for a maximum of 12 months. The following patients were excluded: patients who required thrombectomy, insertion of a caval filter, or use of fibrinolytic agent; patients with $\mathrm{CrCl}<30 \mathrm{~mL} / \mathrm{min}$, significant liver disease (e.g., acute hepatitis, chronic active hepatitis, positive hepatitis $\mathrm{B}$ antigen or hepatitis $\mathrm{C}$ antibody, and cirrhosis) or alanine transaminase (ALT) $>2$ times UNL, total bilirubin 1.5 times UNL, active bleeding or high risk for bleeding, SBP > $170 \mathrm{mmHg}$, or DBP > $100 \mathrm{mmHg}$; pregnant patients; patients with chronic condition requiring treatment with nonsteroidal anti-inflammatory drugs (NSAIDs) including both cyclooxygenase-1 (COX-1) and cyclooxygenase-2 (COX-2) inhibitors for 4 days/week; patients requiring treatment with aspirin in a dosage of $>100 \mathrm{mg} /$ per day or dual antiplatelet therapy (any two antiplatelet agents including aspirin plus any other oral or intravenous (IV) antiplatelet drug); patients requiring treatment with the potent $\mathrm{P}$-gp inhibitors ritonavir, nelfinavir, indinavir, or saquinavir; however, systemic use of the strong P-gp inhibitors erythromycin, azithromycin, clarithromycin, ketoconazole, or itraconazole at the time of randomization was permitted. The primary efficacy outcome (first recurrent VTE or VTE-related death) occurred in 3.2\% in edoxaban and 3.5\% in warfarin groups, HR: $0.89(95 \%$ CI: $0.70-1.33 ; P<0.01$ for noninferiority). The primary safety outcome (first major or CRNM bleeding) occurred in $8.5 \%$ of edoxaban and $10.3 \%$ of warfarin groups, HR: 0.81 (95\% CI: $0.71-0.94 ; P=0.004$ for superiority). Therapeutic INR range occurred in $65 \%$ of patients and adherence to edoxaban was $80 \%$. Approximately $12 \%$ of patients in each arm were treated for 3 months, $26 \%$ for 3 to 6 months, $62 \%$ for greater than 6 months, and $40 \%$ for 12 months. In patients with PE, the rates of recurrent VTE occurred in 3.3\% in the edoxaban group and $6.2 \%$ in the warfarin group, HR: 0.52 (95\% CI: 0.28-0.98) and for those with documented right ventricular dysfunction based on computed tomography the HR of recurrent VTE was 0.42 (95\% CI: $0.15-1.20$ ) in edoxaban versus warfarin. Compared to warfarin, the rate of recurrent VTE in patients on edoxaban $30 \mathrm{mg}$ was $3.0 \%$ versus $4.2 \%$, HR: 0.73 (95\% CI: $0.42-1.26$ ). The rates of arterial thromboembolism in both arms were less than $0.6 \%$ and rates of liver injury were less than $2 \%$ in each arm [37]. The Hokusai-VTE showed noninferiority of edoxaban; however, clinicians should be aware that edoxaban was started after the initial treatment with heparins (5 days) as some patient with life-threatening VTE may require immediate procedures such as thrombectomy with or without thrombolysis. There is no subgroup analysis on edoxaban $60 \mathrm{mg}$ and $30 \mathrm{mg}$ to determine the dose effect on safety and efficacy outcomes. Edoxaban $60 \mathrm{mg}$ orally daily is the approved dose for VTE treatment, unless $\mathrm{CrCl}$ is between 15 and $50 \mathrm{~mL} / \mathrm{min}$ or body weight $<60 \mathrm{~kg}$ or patient was on concomitant Pap inhibitor in which $30 \mathrm{mg}$ orally daily should be used (Table 1) [17].

4.6. Extended Treatment of VTE. The rate of VTE recurrence after discontinuation of therapy has been reported as $11.0 \%$ after 1 year, $19.6 \%$ after 3 years, and $29.1 \%$ after 5 years [66]. The risk of mortality is estimated as $3.6 \%$ for a recurrent VTE and $11.3 \%$ for a major bleed [67]. The ACCP guidelines recommend chronic anticoagulation for patients with recurrent VTE [61]. Although data is available for extended treatment for VTE with apixaban or rivaroxaban $[68,69]$, limited data exists for edoxaban.

4.7. Primary Thromboprophylaxis in Ambulatory Cancer Patients Receiving Chemotherapy. The association of malignancy and VTE is well described [70]. Pancreatic, brain, gastric, esophageal, and renal cell cancers and acute myelogenous leukemia confer a higher cumulative risk of VTE than breast, prostate, and melanoma malignancies [71]. In a population-based cohort of cancer patients with VTE, the cumulative incidence of VTE recurrence was 26.7 to $52.2 \%$ from the incidence of first VTE with mortality of $55.9 \%$ to $85.2 \%$ over 10 years [72]. In a study of cancer patients $(n=$ 3,805 ) with VTE, risk of bleeding was $4.1 \%$ with $29 \%$ mortality. Predictive variables of bleeding were $\mathrm{CrCl} \leq 30 \mathrm{~mL} / \mathrm{min}$, immobility $\geq 4$ days, history of recent major bleeding, and metastatic cancer [73]. Predictive variables such as site of cancer, platelet count $>350,000 / \mathrm{mm}^{3}$, hemoglobin < $10 \mathrm{~g} / \mathrm{dL}$, use of erythropoiesis-stimulating agents, leukocyte 
count $>11 \times 10^{9} / \mathrm{L}$, and body mass index $\geq 35 \mathrm{~kg} / \mathrm{m}^{2}$ may assist in identifying high-risk cancer patients for developing VTE [74]. Although randomized phase II study (tolerability trial) data exists for apixaban in this setting [75], no published data exists for edoxaban.

4.8. Initial Treatment of VTE in Cancer Patients. Enrolling cancer patients in clinical trials of DOACs has posed a challenge for investigators, due to underlying coagulopathy and thrombocytopenia and uncertain prognosis. VTE treatment trials of rivaroxaban enrolled 5 to $7 \%$ active cancer patients (acute DVT and continued treatment), 2.5\% apixaban patients with active cancer, and 9\% edoxaban patients [37, 63-65]. A subgroup analysis of patients enrolled in EINSTEIN-DVT and EINSTEIN-PE with active cancer (diagnosed at baseline or during treatment) has been published. Overall rivaroxaban was deemed similar in efficacy and safety to VKA in a subgroup of cancer patients [76]. Subgroup analysis may create false positive results by decreasing power, alteration of hypothesis, and generation of a mere observation. None of OFXaIs VTE treatment trials were designed to look at cancer patients as a subgroup. A systemic review of 4 randomized controlled phase III trials of 19,060 of which 759 with cancer randomized to either DOAC or SOC demonstrated efficacy (OR: 0.56 (95\% CI: 0.28 to 1.13)) in DOACs versus SOC group. Safety outcomes comparing DOAC to VKA of yielded OR: 0.88 (95\% CI: 0.57 to 1.35 ) [77]. A recent meta-analysis of six studies (two with dabigatran, two with rivaroxaban, one with edoxaban, and one with apixaban) comparing DOACs to SOC for treatment of VTE including patients with cancer demonstrated that VTE recurred in 3.9\% (23/595) and 6\% (32/537) of patients with cancer treated with DOACs and SOC, respectively (OR: 0.63 (95\% CI: $\left.0.37-1.10 ; I^{2} 0 \%\right)$ ). Major bleeding occurred in $3.2 \%$ and $4.2 \%$ of patients receiving DOACs and SOC, respectively (OR: 0.77 (95\% CI: 0.41-1.44; $I^{2}$ 0\%)) [78]. This meta-analysis, despite a high degree of homogeneity $\left(I^{2}=0 \%\right)$, analyzed dabigatran (DTI) in addition to OFXaIs. Dabigatran weight in this meta-analysis was $37 \%$ which might have skewed the results. Dabigatran PD/PK properties are completely different and should not be compared to OFXaI in the absence of direct comparison randomized head-to-head clinical trial in VTE setting. Currently, the American Society of Clinical Oncology (ASCO), National Comprehensive Cancer Network (NCCN), and ACCP recommend $\mathrm{LMWH}$ as the first line and warfarin as the second line for treatment of VTE in cancer patients. These guidelines currently do not recommend DOACs in cancer patients due to lack of randomized clinical trials $[79,80]$. Another point to consider is that none of the trials with DOACs were set to analyze cancer subset data analysis. A phase III study comparing low-molecular-weight heparin versus edoxaban for the treatment of cancer-associated VTE is underway.

\section{Edoxaban Studies in Acute Coronary Syndrome (ACS)}

OFXaIs have been investigated in patients with recent ACS. In the ATLAS-ACS 2-TIMI 51 trial, rivaroxaban reduced the rates of death from cardiovascular causes $(2.7 \%$ versus $4.1 \%, P=0.002$ ) and, compared with placebo, rivaroxaban increased the rates of major bleeding not related to coronary artery bypass grafting $(2.1 \%$ versus $0.6 \%, P<0.001)$ and intracranial hemorrhage $(0.6 \%$ versus $0.2 \%, P=0.009)$, without a significant increase in fatal bleeding $(0.3 \%$ versus $0.2 \%, P=0.66)$ [81]. In the APRAISE-2, addition of apixaban to antiplatelet therapy did not reduce the risk of cardiovascular death, myocardial infarction, or ischemic stroke versus placebo, 13.2 versus $14.0 \%, P=0.51$, but significantly increased the risk of major bleeding (2.4 versus $0.9 \%, P=0.001$ ) [82]. To our knowledge, there is no clinical trial published for the role of edoxaban in patients with ACS.

\section{Prevention of Stroke in Nonvalvular Atrial Fibrillation (NVAF)}

A three-arm, randomized, double-blind, double-dummy trial (ENGAGE AF-TIMI 48) compared once daily edoxaban $(30 \mathrm{mg}$ and $60 \mathrm{mg}$ ) with warfarin in 21,105 patients with NVAF. Patients with an estimated $\mathrm{CrCl}<30 \mathrm{~mL} / \mathrm{min}$, high risk of bleeding, use of dual antiplatelet therapy, moderate to severe mitral stenosis, acute coronary syndromes, stroke within 30 days before randomization, and an inability to adhere to study procedures were excluded. The annual rate of the stroke or systemic embolism during treatment was $1.50 \%$ with warfarin, as compared with $1.18 \%$ with highdose edoxaban (HR: 0.79 (97.5\% CI: 0.63-0.99); $P<0.001$ for noninferiority) and $1.61 \%$ with low-dose edoxaban (HR: 1.07 (97.5\% CI, 0.87-1.31); $P=0.005$ for noninferiority). In the intention-to-treat analysis, there was a trend favoring edoxaban $60 \mathrm{mg}$ versus warfarin (HR: 0.87 (97.5\% CI: $0.73-$ 1.04); $P=0.08$ ) and an unfavorable trend with edoxaban $30 \mathrm{mg}$ versus warfarin (HR: 1.13 (97.5\% CI: 0.96-1.34); $P=$ 0.10 ). The annual rate of major bleeding was $3.43 \%$ with warfarin versus $2.75 \%$ with $60 \mathrm{mg}$ edoxaban (HR: 0.80 (95\% CI: $0.71-0.91) ; P<0.001)$ and $1.61 \%$ with $30 \mathrm{mg}$ edoxaban (HR: 0.47 (95\% CI: 0.41-0.55); $P<0.001$ ). The corresponding annual rates of death from cardiovascular causes were $3.17 \%$ versus $2.74 \%$ (HR: 0.86 (95\% CI: 0.77-0.97); $P=0.01$ ) and 2.71\% (HR: 0.85 (95\% CI: 0.76-0.96); $P=0.008$ ), and the corresponding rates of the key secondary endpoint (a composite of stroke, systemic embolism, or death from cardiovascular causes) were $4.43 \%$ versus $3.85 \%$ (HR: 0.87 (95\% CI: $0.78-0.96) ; P=0.005)$ and $4.23 \%$ (HR: 0.95 (95\% CI: $0.86-1.05) ; P=0.32$ ). Warfarin was within the therapeutic range in $58 \%$ of patients. This study showed noninferiority of edoxaban to SOC and significantly lower bleeding rates in prevention of stroke in patients with NVAF [38]. The subgroup analysis of patients with $\mathrm{CrCl}>95 \mathrm{~mL} / \mathrm{min}$ in ENGAGE AF-TIMI 48 showed higher rates of stroke and systemic embolism events (SEE) in edoxaban versus warfarin 1.0 versus 0.6 (HR: 1.87 (95\% CI: 1.10-3.17)). The rate of ischemic stroke was higher relative to warfarin in the patients with $\mathrm{CrCl}>95 \mathrm{~mL} / \mathrm{min}$ (HR: 2.16 (95\% CI: 1.17, 3.97)). The PK data indicated that patients with $\mathrm{CrCl}>95 \mathrm{~mL} / \mathrm{min}$ had lower plasma edoxaban levels, along with a lower rate of bleeding relative to warfarin than patients with $\mathrm{CrCl} \leq 95 \mathrm{~mL} / \mathrm{min}$. 
Consequently, edoxaban should not be used in patients with $\mathrm{CrCl}>95 \mathrm{~mL} / \mathrm{min}$ [17]. The dose of edoxaban for NVAF is $60 \mathrm{mg}$ orally daily unless $\mathrm{CrCl}$ is $15-50 \mathrm{~mL} / \mathrm{min}$ in which the dose should be decreased to $30 \mathrm{mg}$ (Table 1) [17].

\section{Thrombolysis Management in Edoxaban-Treated Patients Who Develop Acute Ischemic Stroke (AIS)}

Despite edoxaban prophylaxis in NVAF, some patients develop AIS. Intravenous administration of recombinant tissue plasminogen activator (rTPA) is the only FDA-approved therapy for treatment of patients with AIS. The American Heart Association and the American Stroke Association recommend thrombolysis with rTPA in AIS patients with 34.5 hours of onset of stroke symptoms. Data on thrombolysis in edoxaban-treated patients with AIS are very limited. Patients who are already on edoxaban pose many challenges because of increased risk of major bleeding complications when the rTPA is concurrently administered. Unless rapidly performed PT, aPTT, and appropriate direct factor Xa activity assays are normal or the patient has not received a dose for $>2$ days (assuming normal renal function), AHA/ASA guidelines do not recommend thrombolysis. Unfortunately, most of the tests are time-consuming to meet the 3-4.5-hour thrombolysis window [83].

\section{Measurement of the Anticoagulant Effect of Edoxaban}

The effect of edoxaban levels on coagulation parameters such as PT (prothrombin time), INR (international normalized ratio), aPTT (activated partial thromboplastin time), and factor Xa has not been extensively studied. An ex vivo study of 12 healthy volunteers assessed the antithrombotic effect of edoxaban $60 \mathrm{mg}$ on coagulation parameters. Thrombin generation decreased by $28 \%$ and $10 \%$ at 1.5 hours and 10 hours. Changes in PT, INR, and anti-FXa activity correlated well with plasma drug concentrations $\left(R^{2}=0.79,0.78\right.$, and $0.85)$, but aPTT changes did not $\left(R^{2}=0.40\right)$. Drug levels at $1.5,5$, and 12 hours after edoxaban $60 \mathrm{mg}$ were $240 \pm 16$, $127 \pm 6$, and $37 \pm 3 \mathrm{ng} / \mathrm{mL}$. The effect of drug level on the thrombus size reduction was not measured [84]. Edoxaban concentration in plasma after multiple dose administration has been evaluated. Edoxaban $90 \mathrm{mg}$ daily provided $C_{\max / \min }$ for day 1 as $451 / 10.2(\mathrm{ng} / \mathrm{mL})$ and $424 / 16.4(\mathrm{ng} / \mathrm{mL})$ on day 10. Edoxaban $60 \mathrm{mg}$ twice daily achieved $C_{\max } / \mathrm{min}$ of $347 / 38.3(\mathrm{ng} / \mathrm{mL})$ on day 1 and $397 / 80.3(\mathrm{ng} / \mathrm{mL})$ on day 10. Finally, edoxaban $120 \mathrm{mg}$ daily showed $C_{\max / \min }$ of $387 / 11.1(\mathrm{ng} / \mathrm{mL})$ on day 1 and $406 / 15.6(\mathrm{ng} / \mathrm{mL})$ on day 10 [18]. A phase 2 study on edoxaban for prevention of stroke in NVAF measured the $C_{\max / \min }$ of edoxaban in 1,146 patients. At steady state, the median $C_{\max / \min }$ was $80 / 10(\mathrm{ng} / \mathrm{mL})$ for edoxaban $10 \mathrm{mg}$ daily, 175/20 (ng/mL) for edoxaban $60 \mathrm{mg}$ daily, $120 / 40(\mathrm{ng} / \mathrm{mL})$ for edoxaban $30 \mathrm{mg}$ twice daily, and 225/75 (ng/mL) for edoxaban $60 \mathrm{mg}$ twice daily. This study showed higher bleeding rates with higher total daily doses of edoxaban. Interestingly, $C_{\text {min }}$ correlated more closely with bleeding; that is, frequency of bleeding was higher with edoxaban $30 \mathrm{mg}$ twice daily versus edoxaban $60 \mathrm{mg}$ daily. No analysis of edoxaban level on primary outcome such as stroke was evaluated [85]. A recent study has shown the significant variation is prolonged in PT and aPTT postedoxaban dose diluted to reach plasma concentrations of $50-400 \mathrm{ng} / \mathrm{mL}$. The PT prolongation remained variable and dependent on specific reagent, but prolonged aPTT variability remained smaller; however, thrombin generation assay proved to be sensitive [86]. Differences in $\mathrm{PK}$ variables $\left(T_{\max }, C_{\max }\right.$, and $C_{\text {min }}$ ) in edoxaban studies have been observed. There is no consensus at this point to make recommendations for monitoring edoxaban in special populations (obesity, underweight, and renal insufficiency). Lack of a standardized assay to monitor FXa poses a dilemma for clinicians assessing safety and efficacy of treatment with edoxaban.

\section{Management of Bleeding Complications}

Bleeding is a complication of anticoagulation therapy. Availability of antidote can prevent potential unfavorable outcomes associated with hemorrhagic events. Rates of major bleeding in edoxaban group versus warfarin group have been reported as $1.4 \%$ versus $1.6 \%$ in a VTE treatment trial [37]. In the setting of NVAF, the rates of major bleeding with high-dose edoxaban (60 mg daily) group were $2.75 \%$ per year versus $1.61 \%$ per year in low-dose edoxaban $(30 \mathrm{mg}$ daily) (Table 5) [38]. To date, there are not any clinical trials investigating the reversal of edoxaban in humans. In an edoxaban-anticoagulated animal study, the prothrombin complex concentrate (PCC), recombinant factor VIIa (rFVIIa), and activated prothrombin complex concentrate (aPCC) shortened PT prolonged by edoxaban. Among those, rFVIIa and aPCC showed potent activities in reversing the PT prolongation by edoxaban. rFVIIa ( 1 and $3 \mathrm{mg} / \mathrm{kg}$ ) and aPCC (100 U/kg) significantly reversed edoxaban $(1 \mathrm{mg} / \mathrm{kg} / \mathrm{h})$ induced prolongation of bleeding time. In venous thrombosis model, no potentiation of thrombus formation was observed when the highest dose $(3 \mathrm{mg} / \mathrm{kg})$ of rFVIIa was added to edoxaban $(0.3$ and $1 \mathrm{mg} / \mathrm{kg} / \mathrm{h})$ compared with the control. This study indicated that rFVIIa, aPCC, and PCC have the potential to be reversal agents for edoxaban [87]. In a rabbit model acute hemorrhage induced by edoxaban, blood loss was increased to $30 \mathrm{~mL}(2-44)$ and time to reach hemostasis was prolonged by 23 minutes (8.5-30) versus control group. Administration of 4F-PCC significantly reduced time to hemostasis to 8 minutes (6.5-14), $P<0.0001$, versus control. In this study, PT (seconds) was $9.7 \pm 0.9$ in glucose saline $5 \%$ group versus $17.4 \pm 1.7$ in edoxaban $1,200 \mu \mathrm{g} / \mathrm{kg}$ saline group, $P<0.0001$. Addition of 4 F-PCC (50 IU $/ \mathrm{kg}$ ) lowered the PT (s) to $13.5 \pm 0.7, P<0.0001$. This study confirmed that 4F-PCC effectively normalizes PT [88]. Edoxaban (500 or $1,000 \mathrm{ng} / \mathrm{mL}$ ) was added to blood sample from 6 healthy volunteers followed by rFVIIa $(0.8$ or $1.8 \mu \mathrm{g} / \mathrm{mL})$ or factor VIII inhibitor bypassing agent (FEIBA $(0.75$ or $1.5 \mathrm{U} / \mathrm{mL})$ ). In edoxaban-containing blood samples, reductions in measures of PT $(P<0.0001)$, aPTT $(P<0.0001)$, and anti-FXa $(P<0.0001)$ were observed when rFVIIa or aPCC was added. Intrinsic FXa activity was increased up to $20 \%$ and $31 \%$ of 
normal in the presence of edoxaban by rFVIIa and aPCC, accordingly. The onset of their impact on the anticoagulant effects of edoxaban was observed within 15 minutes and remained relatively unchanged. Results of this ex vivo study suggest that rFVIIa and aPCC rapidly reversed edoxabanmediated anticoagulation effects based on PT and aPTT but had minimal effect based on intrinsic FX activity [89]. In acute overdose, if ingestion is within 3 hours, activated charcoal (50-100 gm) can be given along with fluid and red blood cell resuscitation [90]. Overall, the administration of 4-FPCC (50 units/kg) and aPCC (50 units/kg) and addition of rVIIa $(90 \mu \mathrm{g} / \mathrm{kg})$ in refractory cases have been shown in animal studies to normalize thrombin generation, decrease $\mathrm{PT}$, and reduce bleeding time. In a recent study of 110 healthy subjects (17 in part one and 93 in part two), the effect of 4 -FPCC $(50,25$, and $10 \mathrm{IU} / \mathrm{kg})$ on edoxaban $(60$ and $180 \mathrm{mg}$ ) was evaluated in a double-blind, randomized, placebo, 2-way crossover design. Patients were excluded if they were on strong inhibitors or inducers of CYP3A4 or P-gp within the past 28 days, if they had recent major or minor bleeding, and if they had history of coagulopathy. The effects of 4-FPCC on bleeding duration (BD) and bleeding volume (BV) and PT were assessed. BD (minutes) and BV $(\mathrm{mL})$ were completely reversed (above $100 \%$ ) by 4 -FPCC (50 IU/kg); however, PT did not (less than 50\%). 4-FPCC (25 IU/kg) effect on BD, BV, and PT was suboptimal (less than $75 \%)$ and 4 -FPCC (10 IU/kg) had no effect on BD, BV, and PT. No death or thrombotic events were reported. 4FPCC demonstrated complete reversal effect of edoxaban on coagulation parameters [91, 92]. Currently, there are no specific antidotes for OFXaIs; however, 2 investigational antidotes are in phase 2 clinical trials. Andexanet alfa, a modified recombinant $\mathrm{FXa}$, with terminal $T_{1 / 2}$ of $\sim 6$ hours binds to OFXaIs specifically, thereby neutralizing its anticoagulant effects. Aripazine, a small synthetic molecule, universally targets OFXaIs, LMWHs, thrombin inhibitor (IIaI), and fondaparinux by binding them. Upcoming large scale trials should shed light onto these antidotes' safety and efficacy [93].

\section{Drug-Drug Interactions with Edoxaban}

Drug-drug or dietary supplement interactions with edoxaban may potentially predispose patients to bleeding or thromboembolism. Edoxaban's metabolism involves a major pathway via permeability glycoprotein (P-gp; ATP-binding cassette, subfamily $\mathrm{B}$, membrane 1 , or multidrug resistance1 (MDR1)) transporter of the intestinal lining and a minor pathway of CYP3A4 [22]. Therefore, drugs that inhibit the P-gp pump can increase the level of edoxaban and drugs that induce the P-gp pump can lower the edoxaban level [23]. The addition of other antithrombotic or nonsteroidal anti-inflammatory agents to edoxaban may enhance the bleeding effect and combination should be avoided. Patients on edoxaban with recent coronary stent (on dual antiplatelet: aspirin and clopidogrel) may require lower doses of aspirin. Some inducers of P-gp transporter such as rifampin and St. John's Wort will lower the plasma concentration of edoxaban should be avoided. Cardiac medications such as verapamil and quinidine that are $\mathrm{P}$-gp inhibitors require dose adjustment of edoxaban by $50 \%$. Potent inhibitors of P-gp such as lansoprazole, omeprazole, azithromycin, erythromycin, ketoconazole, and itraconazole require $50 \%$ dose reduction of edoxaban if coadministered. Dose reduction of edoxaban is required if concomitant use of cardiac agents such as amiodarone or dronedarone (P-gp inhibitors) is warranted. Vascular endothelial growth factor (VEGF) inhibitors such as pazopanib, lapatinib, and sorafenib could potentially increase edoxaban plasma levels via P-gp inhibition. Dietary supplements such as vitamin E ( $>800$ units per day) and fish oil can inhibit platelet aggregation and their combination with edoxaban may predispose patient to bleeding. There are supplements that have warfarin derivatives such as sweet clover, chamomile, and horseradish that should be avoided in combination with edoxaban, Table 2 [17, 24-29]. Patients on edoxaban should be counselled on drug or dietary supplement interactions.

\section{Perioperative Management of Edoxaban Therapy}

Clinicians should recognize that the data for use of edoxaban in perioperative setting is limited. Unless an emergent surgery is planned, elective surgery cases for patients on edoxaban require assessment of the risk of perioperative thromboembolism and the risk of bleeding. This assessment aids in determining the need for perioperative bridging with shortacting anticoagulants in the immediate perioperative setting. Patients with atrial fibrillation CHADS $_{2}$ (congestive heart failure, hypertension, age, diabetes, and stroke) score of 0 to 2, without prior history of stroke or transient ischemic attack (TIA)) and remote VTE event (history of more than 1 year in the past) are considered at low risk (less than $4 \%$ per year risk for ATE or less than $2 \%$ per month risk for VTE). This low-risk group does not require bridging. Patients with atrial fibrillation CHADS $_{2}$ score of 3 or 4$)$, VTE (within the past 3 to 12 months), recurrent VTE, nonsevere thrombophilia, and active cancer disease are considered to be at intermediate risk ( 4 to $10 \%$ per year risk for ATE or 4 to $10 \%$ per month risk for VTE). This group may require bridging if bleeding risk is deemed low. Finally, patients with recent ( $<6$ months) history of stroke or TIA, atrial fibrillation $\left(\mathrm{CHADS}_{2}\right.$ score $>5,<3$ months history of stroke or TIA, and rheumatic valvular heart diseases), recent history of VTE ((history of $<3$ months), severe thrombophilia, being positive for antiphospholipid antibodies, proteins $\mathrm{C}$ and $\mathrm{S}$ deficiency, and antithrombin deficiency) carry risk exceeding $10 \%$ per year for ATE and $10 \%$ per month for VTE. These patients require bridging with short-acting anticoagulants [30]. Once the patient was deemed an appropriate candidate for bridging, bleeding risk associated with procedure should be estimated as some procedures carry a higher risk of bleeding (major surgeries and renal biopsy) than simple dental extraction. For procedure with lower risk of bleeding, aiming for mild to moderate residual anticoagulant effect at surgery $(12 \%-25 \%)$ or $2-3$ half-lives should suffice, whereas for higher bleeding risk procedure, aiming for no or minimal 


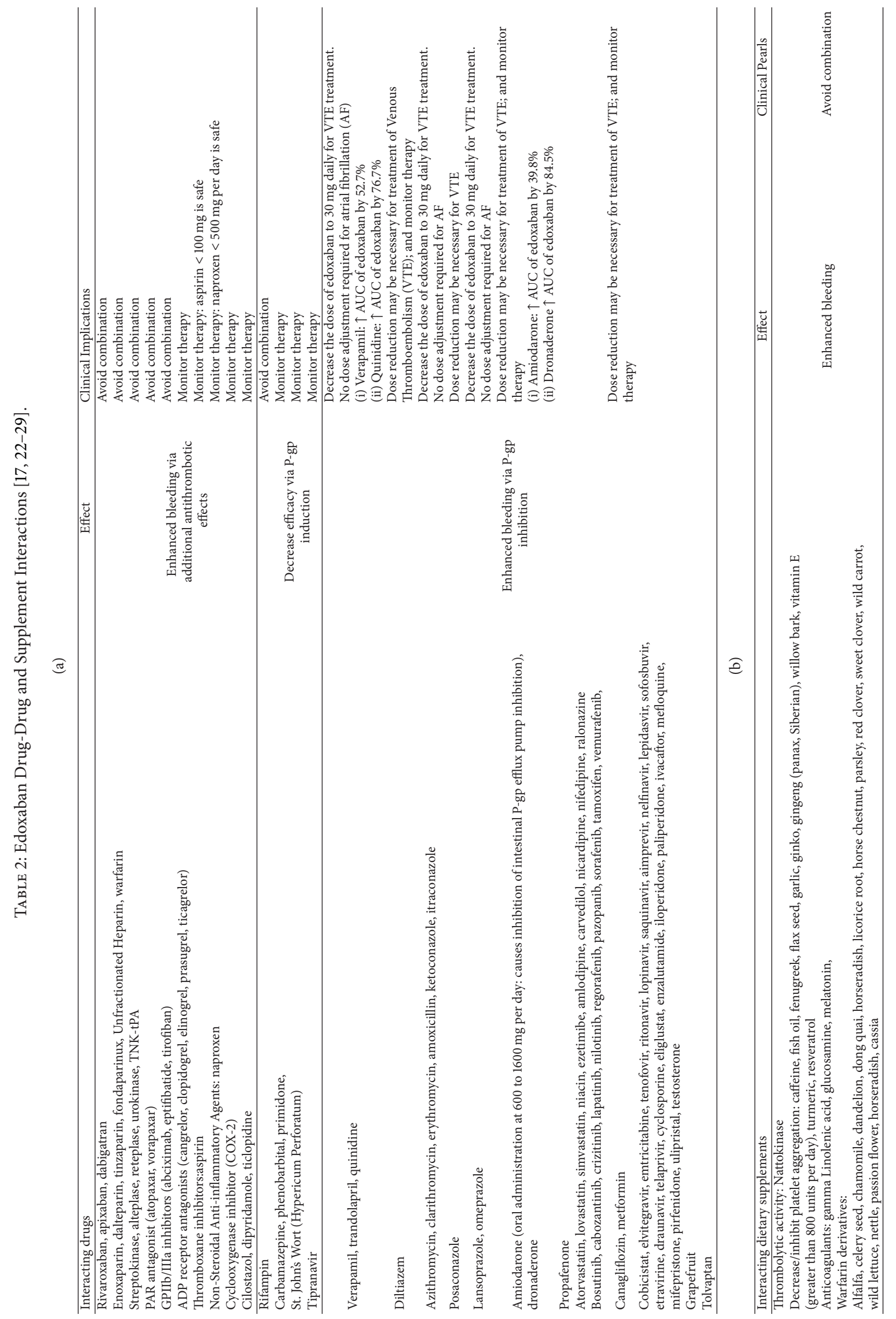


TABLE 3: Interruption/holding of edoxaban for procedures [17, 30, 31].

\begin{tabular}{|c|c|c|c|}
\hline & $T_{1 / 2}$ & $\begin{array}{l}\text { Low risk or minor surgery } \\
\text { (procedures with 2-day risk for major } \\
\text { bleeding } 0-2 \% \text { ) } \\
\downarrow \\
\text { Aiming for mild to moderate residual } \\
\text { anticoagulant effect at surgery }(12 \%-25 \%) \\
\text { or } 2-3 \text { half-lives }\end{array}$ & $\begin{array}{l}\text { High risk or major surgery } \\
\text { (procedures with 2-day risk for major } \\
\text { bleeding } 2 \%-4 \% \text { ) } \\
\downarrow \\
\text { Aiming for no or minimal residual } \\
\text { anticoagulant effect }(3 \%-6 \% \text { ) at surgery } \\
\text { or } 4-5 \text { half-lives }\end{array}$ \\
\hline Edoxaban & $10-14 \mathrm{hr}$ & $24 \mathrm{hr}$ & $48-72 \mathrm{hr}$ \\
\hline Types of surgical procedures & & $\begin{array}{l}\text { (i) Cholecystectomy } \\
\text { (ii) Abdominal hernia repair } \\
\text { (iii) Abdominal hysterectomy } \\
\text { (iv) Coronary angiography/percutaneous } \\
\text { coronary intervention } \\
\text { (v) Electrophysiologic testing } \\
\text { (vi) Pacemaker/cardiac defibrillator } \\
\text { insertion } \\
\text { (vii) Gastrointestinal endoscopy } \pm \text { biopsy, } \\
\text { enteroscopy, biliary/pancreatic stent } \\
\text { without sphincterotomy, and } \\
\text { endosonography without aspiration } \\
\text { (viii) Minor plastic surgery (carpal tunnel } \\
\text { repair) } \\
\text { (ix) Minor orthopedic } \\
\text { surgery/arthroscopy } \\
\text { (x) Minor gynecologic surgery (dilation } \\
\text { and curettage) } \\
\text { (xi) Minor dental procedures } \\
\text { (extractions) } \\
\text { (xii) Minor skin procedures (cancer } \\
\text { excision) } \\
\text { (xiii) Minor eye procedures (cataract) }\end{array}$ & $\begin{array}{l}\text { (i) Major cardiac surgery (surgical heart } \\
\text { valve replacement/coronary artery bypass } \\
\text { grafting) } \\
\text { (ii) Major neurosurgical procedures } \\
\text { (iii) Major cancer surgery (head and } \\
\text { neck/abdominal/thoracic) } \\
\text { (iv) Major orthopedic surgery (joint } \\
\text { replacement/laminectomy) } \\
\text { (v) Major urologic surgery } \\
\text { (prostate/bladder resection) } \\
\text { (vi) Major vascular surgery } \\
\text { (vii) Kidney biopsy } \\
\text { (viii) Polypectomy, variceal treatment, } \\
\text { biliary sphincterectomy, and pneumatic } \\
\text { dilation } \\
\text { (ix) Endoscopically guided fine-needle } \\
\text { aspiration }\end{array}$ \\
\hline
\end{tabular}

Creatinine clearance, $\mathrm{CrCl}$.

residual anticoagulant effect $(3 \%-6 \%)$ at surgery or $4-5$ halflives should suffice; therefore, edoxaban interruption can range from 24 to 72 hours (Table 3 ). If the patient is unable to tolerate oral tablets (prolonged nothing by mouth state) in the immediate postoperative period, transition $\mathrm{LMWH}$ or UFH infusion might be appropriate. Some institutions may not carry edoxaban due to formulary restrictions; in these situations, transition to other antithrombotics could be implemented $[17,31]$. In order to assure a safe and effective practice, it is prudent to develop specific institutional guidelines or clinical practice algorithms for management of DOACs in the perioperative period by a multidisciplinary group compromising internists, surgeons, nursing staffs, and pharmacists.

\section{Transition to Other Anticoagulants}

Currently, there is no published trial evaluating the safety and efficacy role of bridging with edoxaban in the perioperative setting or transition to other antithrombotics. Transition to and from edoxaban requires estimation of $\mathrm{CrCl}$ and $\mathrm{PK}$ parameters such as $T_{1 / 2}$ of each of the antithrombotics, monitoring INR and aPTT when necessary. Table 4 will provide guidance to clinicians when bridging to and from edoxaban is required. Patients should be given a complete calendar and education of transition to and from edoxaban [17].

\section{Current Approval Status}

Edoxaban has been approved to reduce the risk of stroke or systemic embolism in patients with NVAF and for treatment of deep vein thrombosis and pulmonary embolism in USA, European Union, and Japan. Edoxaban has been approved for prophylaxis of deep vein thrombosis following orthopedic surgery in Japan. Edoxaban should not be used in patients with mechanical heart valves as no research trial has been conducted in this population. Dabigatran, an oral DTI, has been shown to be inferior to warfarin in reducing systemic embolism in this clinical setting [94].

\section{Patient Satisfaction}

Curtailing the need for frequent INR monitoring and administration of oral tables rather than injections could possibly improve patient compliance and satisfaction with anticoagulant therapy. Anti-Clot Treatment Scale (ACTS: burdens score range 12-60; benefits score range 3-15) and Treatment Satisfaction Questionnaire for Medication (TSQM: effectiveness; side effects; convenience, global satisfaction score 
TABle 4: (a) Transition to edoxaban [17]. (b) Transition from edoxaban [17].

(a)

\begin{tabular}{|c|c|c|}
\hline From & To & Recommendation \\
\hline Warfarin & \multirow{3}{*}{ Edoxaban } & Discontinue warfarin and start edoxaban when INR $\leq 2.5$ \\
\hline $\begin{array}{l}\text { Rivaroxaban, apixaban } \\
\text { Dabigatran }\end{array}$ & & $\begin{array}{l}\text { Discontinue current oral anticoagulant and start edoxaban at the time of } \\
\text { the next scheduled dose of the other oral anticoagulant }\end{array}$ \\
\hline $\begin{array}{l}\text { Low-molecular-weight } \\
\text { heparin (LMWH) } \\
\text { Fondaparinux }\end{array}$ & & $\begin{array}{l}\text { Discontinue LMWH or fondaparinux and start edoxaban at the time of the } \\
\text { next scheduled administrastion of LMWH or fondaparinux }\end{array}$ \\
\hline $\begin{array}{l}\text { Heparin Intravenous } \\
\text { Infusion (IVI) }\end{array}$ & & Discontinue the infusion and start edoxaban 4 hours later \\
\hline
\end{tabular}

(b)

\begin{tabular}{|c|c|c|}
\hline From & To & Recommendations \\
\hline \multirow[t]{3}{*}{ Edoxaban } & Warfarin & $\begin{array}{l}\text { (1) Oral option: } \\
\text { (i) For patients taking } 60 \mathrm{mg} \text { of edoxaban, reduce the dose to } 30 \mathrm{mg} \text { and begin warfarin } \\
\text { concomitantly. } \\
\text { (ii) For patients receiving } 30 \mathrm{mg} \text { of edoxaban, reduce the dose to } 15 \mathrm{mg} \text { and begin warfarin } \\
\text { concomitantly. } \\
\text { (iii) INR must be measured at least weekly and just prior to the daily dose of edoxaban to } \\
\text { minimize the influence of edoxaban on INR measurements. } \\
\text { (iv) Once a stable INR greater or equal to } 2.0 \text { is achieved, edoxaban should be discontinued and } \\
\text { the warfarin continued. } \\
\text { (2) Parenteral option: } \\
\text { (i) Discontinue edoxaban and administer a parenteral anticoagulant and warfarin at the time of } \\
\text { the next scheduled edoxaban dose. } \\
\text { (ii) Once a stable INR greater or equal to } 2.0 \text { is achieved, the parenteral anticoagulant should } \\
\text { be discontinued and the warfarin continued. }\end{array}$ \\
\hline & $\begin{array}{c}\text { Apixaban } \\
\text { Rivaroxaban } \\
\text { Dabigatran }\end{array}$ & $\begin{array}{l}\text { Discontinue edoxaban and start the other anticoagulant at the time of the next dose of } \\
\text { edoxaban. }\end{array}$ \\
\hline & $\begin{array}{c}\text { LMWH } \\
\text { Fondaparinux } \\
\text { Heparin IV }\end{array}$ & $\begin{array}{l}\text { Discontinue edoxaban and start the parenteral anticoagulant at the time of the next dose of } \\
\text { edoxaban. }\end{array}$ \\
\hline
\end{tabular}

range $0-100)$ are two frequently validated tools to assess the patient's satisfaction with anticoagulation and higher score equals higher satisfaction. In EINSTEIN-PE, mean ACTS for burdens score was 55.4 in rivaroxaban group and 51.9 in SOC group, $P<0.0001$. The mean ACTS scores for benefits were 11.9 for rivaroxaban group and 11.4 for SOC group, $P<0.0001$. TSQM scores for effectiveness, side effects, convenience, and global satisfaction were 73.3, 86.6, 81.6, and 80.7 for rivaroxaban, versus $69.6,82.3,71.8$, and 73.0 for SOC group, $P<0.0001$, for all groups [95]. In EINSTEINDVT significant benefits in terms of ACTS and TSQM scores were observed in rivaroxaban versus warfarin, $P<0.0001$ [96]. One could presume the same satisfaction scores or even higher for edoxaban since it is dosed once daily. Future trials should provide additional evidence for benefits of edoxaban in terms of patient satisfaction.

\section{Economic Impact}

Recently, the cost-effectiveness of OFXaIs in orthopedic surgery patients has been investigated in a pharmacoeconomic decision model. In THR replacement model, the average cost per patient for LMWHs and that for oral FXa-Is were $\$ 18,897$ and $\$ 18,762$ accordingly; and qualityadjusted life-years (QALY) were 0.932 and 0.938. In TKR model, the average cost for LMWHs and that for oral FXa-Is were $\$ 18,891$ and $\$ 18,804$, respectively, with QALYs of 0.931 and 0.935 for LMWHs and OFXaIs, respectively. Overall sensitivity analysis indicated cost-effectiveness of OFXAIs is greater in $98 \%$ of patients undergoing major orthopedic surgery with the assumption of willingness-to-pay threshold of $\$ 50,000 /$ QALY. Authors concluded that OFXaIs may be economically superior to LMWHs for VTE prevention in orthopedic surgery patients [97]. A recent pharmacoeconomic study examined the cost differences between DOACs and warfarin for treatment of atrial fibrillation and treatment of VTE in a hypothetical patient population. The incidence and prevalence of primary efficacy outcomes (ischemic stroke, hemorrhagic stroke, and systemic embolism), secondary efficacy outcomes (myocardial infarction, pulmonary embolism, and deep vein thrombosis), and safety endpoints (major bleeding and clinically relevant nonmajor bleeding) were extracted from all clinical trials of DOACs (dabigatran, rivaroxaban, apixaban, and edoxaban). Total medical cost 


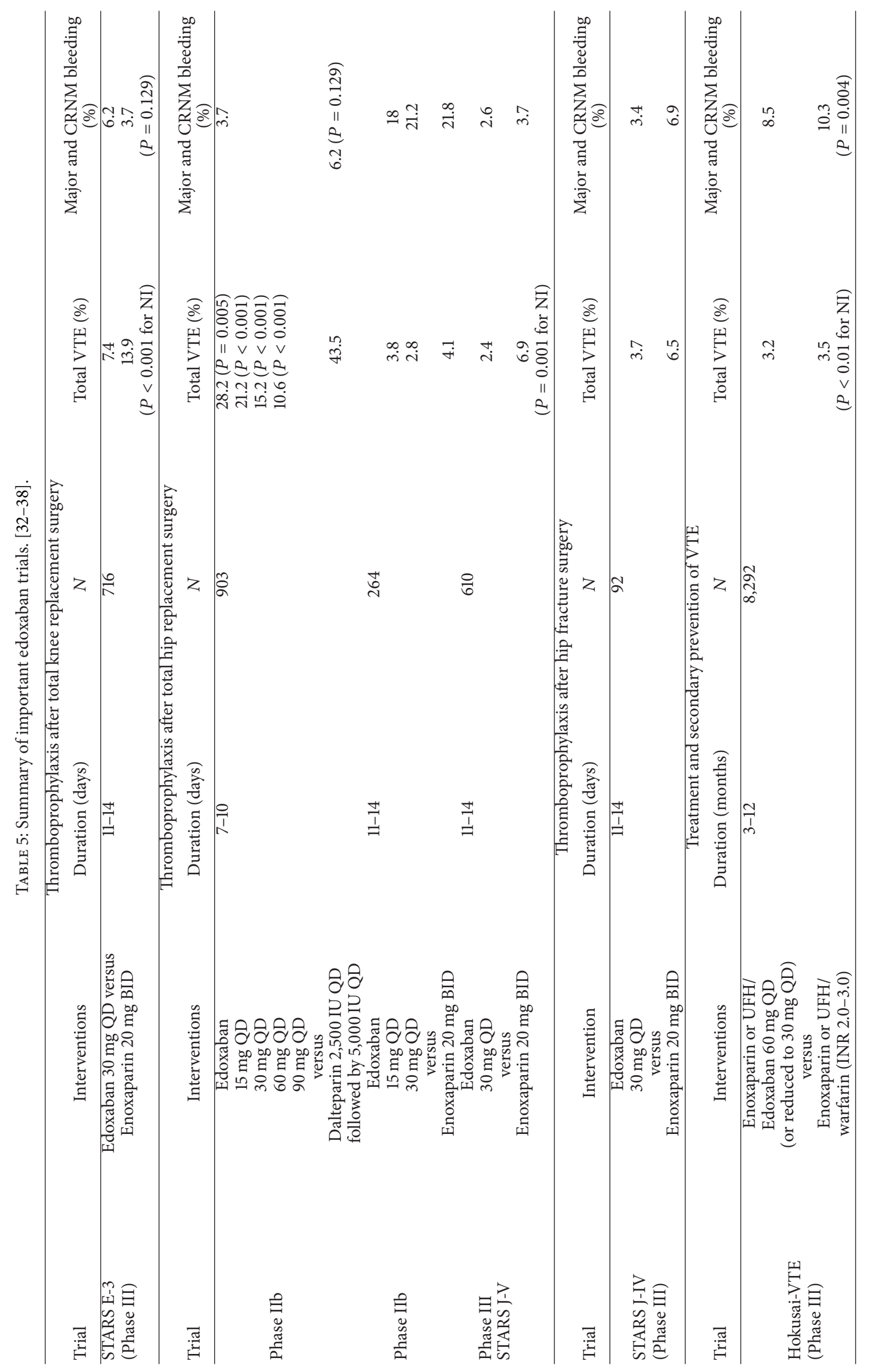




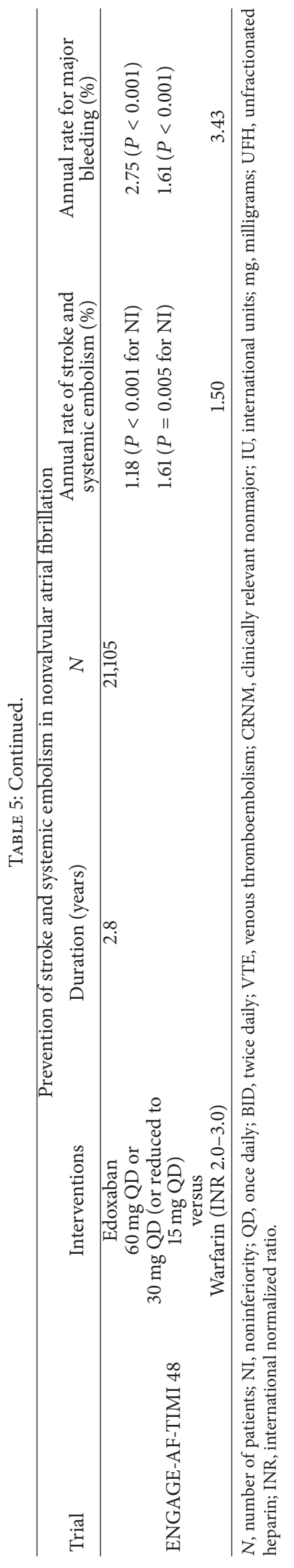


difference measured as dollars/patient-years was -\$204 for dabigatran versus warfarin, $-\$ 140$ for rivaroxaban versus warfarin, $-\$ 495$ for apixaban versus warfarin, and $-\$ 340$ for edoxaban versus warfarin [98]. These results are promising; however, one must consider the acquisition cost differences across states and institutions and payer preference based on contracts.

\section{Patient Education}

Clinicians should become familiar with approved indications, pharmacodynamics, and pharmacokinetic properties of OFXaIs, duration of therapy, screen for drug interactions, communicate with other providers involved when an OFXaI is prescribed, and conduct a comprehensive patient education. Patient education should include signs and symptoms of bleeding, fall and injury precautions, reminders for the exact dose (color of the pill and frequency), and education on missed doses. Instructions on periodic monitoring of renal function, hemoglobin level, and platelet counts should be given to patients with significant comorbidities. There should be a plan of action in place, if pregnancy or planned procedures that require interruption of OFXaI occur.

\section{Conclusion}

Edoxaban seems safe and effective for prevention and treatment of VTE and prevention of stroke in NVAF. Edoxaban might be financially cost-effective and an attractive option compared to injections or warfarin. Edoxaban might provide better patient compliance and satisfaction with antithrombotic therapy. There is clearly lack of evidence for its role in cancer patients, perioperative bridging, transition to other anticoagulants, FXa monitoring, and reversibility for bleeding cases.

\section{Conflict of Interests}

The authors do not report any conflict of interests regarding this work.

\section{References}

[1] D. Wardrop and D. Keeling, "The story of the discovery of heparin and warfarin," British Journal of Haematology, vol. 141, no. 6, pp. 757-763, 2008.

[2] J. Hirsh, M. O'Donnell, and J. W. Eikelboom, "Beyond unfractionated heparin and warfarin: current and future advances," Circulation, vol. 116, no. 5, pp. 552-560, 2007.

[3] J. van Ryn, A. Goss, N. Hauel et al., "The discovery of dabigatran etexilate," Frontiers in Pharmacology, vol. 4, article 12, Article ID Article 12, 2013.

[4] P. C. Wong, D. J. P. Pinto, and D. Zhang, "Preclinical discovery of apixaban, a direct and orally bioavailable factor Xa inhibitor," Journal of Thrombosis and Thrombolysis, vol. 31, no. 4, pp. 478492, 2011.

[5] E. Perzborn, S. Roehrig, A. Straub, D. Kubitza, and F. Misselwitz, "The discovery and development of rivaroxaban, an oral, direct factor Xa inhibitor," Nature Reviews Drug Discovery, vol. 10, no. 1, pp. 61-75, 2011.

[6] C. H. Yeh, J. C. Fredenburgh, and J. I. Weitz, "Oral direct factor Xa inhibitors," Circulation Research, vol. 111, no. 8, pp. 10691078, 2012.

[7] L. Loffredo, L. Perri, M. Del Ben, F. Angelico, and F. Violi, "New oral anticoagulants for the treatment of acute venous thromboembolism: are they safer than vitamin $\mathrm{K}$ antagonists? A meta-analysis of the interventional trials," Internal and Emergency Medicine, 2014.

[8] A. Zalpour and T. H. Oo, "Clinical utility of apixaban in the prevention and treatment of venous thromboembolism: current evidence," Journal of Drug Design, Development and Therapy, vol. 8, pp. 2181-2191, 2014.

[9] D. M. Monroe, "Basic principles underlying coagulation," in Practical Hemostasis and Thrombosis, N. Key, M. Makris, D. O'Shaughnessy, and D. Lillicrapt, Eds., pp. 1-6, Wiley-Blackwell, Oxford, UK, 2nd edition, 2009.

[10] D. Gailani and T. Renné, "Intrinsic pathway of coagulation and arterial thrombosis," Arteriosclerosis, Thrombosis, and Vascular Biology, vol. 27, no. 12, pp. 2507-2513, 2007.

[11] N. Mackman, R. E. Tilley, and N. S. Key, "Role of the extrinsic pathway of blood coagulation in hemostasis and thrombosis," Arteriosclerosis, Thrombosis, and Vascular Biology, vol. 27, no. 8, pp. 1687-1693, 2007.

[12] V. Toschi and M. Lettino, "Inhibitors of propagation of coagulation: factors V and X," British Journal of Clinical Pharmacology, vol. 72, no. 4, pp. 563-580, 2011.

[13] F. Scaglione, "New oral anticoagulants: comparative pharmacology with vitamin K antagonists," Clinical Pharmacokinetics, vol. 52, no. 2, pp. 69-82, 2013.

[14] J. Hirsh and M. N. Levine, "Low molecular weight heparins," Blood, vol. 79, no. 1, pp. 1-17, 1992.

[15] K. G. Mann, K. Brummel, and S. Butenas, "What is all that thrombin for?" Journal of Thrombosis and Haemostasis, vol. 1, no. 7, pp. 1504-1514, 2003.

[16] G. Escolar, M. Diaz-Ricart, E. Arellano-Rodrigo, and A. M. Galán, "The pharmacokinetics of edoxaban for the prevention and treatment of venous thromboembolism," Expert Opinion on Drug Metabolism and Toxicology, vol. 10, no. 3, pp. 445-458, 2014.

[17] Edoxaban Prescribing Information, 2015, http://www.accessdata.fda.gov/drugsatfda_docs/label/2015/206316lbl.pdf.

[18] K. Ogata, J. Mendell-Harary, M. Tachibana et al., "Clinical safety, tolerability, pharmacokinetics, and pharmacodynamics of the novel factor Xa inhibitor edoxaban in healthy volunteers," Journal of Clinical Pharmacology, vol. 50, no. 7, pp. 743-753, 2010.

[19] M. S. Bathala, H. Masumoto, T. Oguma, L. He, C. Lowrie, and J. Mendell, "Pharmacokinetics, biotransformation, and mass balance of edoxaban, a selective, direct factor xa inhibitor, in humans," Drug Metabolism \& Disposition, vol. 40, no. 12, pp. 2250-2255, 2012.

[20] H. Bounameaux and A. J. Camm, "Edoxaban: an update on the new oral direct factor Xa inhibitor," Drugs, vol. 74, no. 11, pp. 1209-1231, 2014.

[21] O. Q. P. Yin and R. Miller, "Population pharmacokinetics and dose-exposure proportionality of edoxaban in healthy volunteers," Clinical Drug Investigation, vol. 34, no. 10, pp. 743752, 2014. 
[22] J. D. Wessler, L. T. Grip, J. Mendell, and R. P. Giugliano, "The P-glycoprotein transport system and cardiovascular drugs," Journal of the American College of Cardiology, vol. 61, no. 25, pp. 2495-2502, 2013.

[23] T. Mikkaichi, Y. Yoshigae, H. Masumoto et al., "Edoxaban transport via P-glycoprotein is a key factor for the drug's disposition," Drug Metabolism and Disposition, vol. 42, no. 4, pp. 520-528, 2014.

[24] O. Yousuf and D. L. Bhatt, "The evolution of antiplatelet therapy in cardiovascular disease," Nature Reviews Cardiology, vol. 8, no. 10, pp. 547-559, 2011.

[25] J. Yeung and M. Holinstat, "Newer agents in antiplatelet therapy: a review," Journal of Blood Medicine, vol. 3, pp. 33-42, 2012.

[26] E. Nutescu, I. Chuatrisorn, and E. Hellenbart, "Drug and dietary interactions of warfarin and novel oral anticoagulants: an update," Journal of Thrombosis and Thrombolysis, vol. 31, no. 3, pp. 326-343, 2011.

[27] J. Mendell, F. Lee, S. Chen, V. Worland, M. Shi, and M. M. Samama, "The effects of the antiplatelet agents, aspirin and naproxen, on pharmacokinetics and pharmacodynamics of the anticoagulant edoxaban, a direct factor xa inhibitor," Journal of Cardiovascular Pharmacology, vol. 62, no. 2, pp. 212-221, 2013.

[28] J. D. Wessler, L. T. Grip, J. Mendell, and R. P. Giugliano, "The P-glycoprotein transport system and cardiovascular drugs," Journal of the American College of Cardiology, vol. 61, no. 25, pp. 2495-2502, 2013.

[29] April 2015, https://www.clinicalpharmacology.com.

[30] J. D. Douketis, A. C. Spyropoulos, F. A. Spencer et al., "Perioperative management of antithrombotic therapy. Antithrombotic therapy and prevention of thrombosis, 9th ed: American College of Chest Physicians evidence-based clinical practice guidelines," Chest, vol. 141, no. 2, supplement, pp. e326S-e350S, 2012.

[31] A. C. Spyropoulos and J. D. Douketis, "How I treat anticoagulated patients undergoing an elective procedure or surgery," Blood, vol. 120, no. 15, pp. 2954-2962, 2012.

[32] T. Fuji, C.-J. Wang, S. Fujita et al., "Safety and efficacy of edoxaban, an oral factor Xa inhibitor, versus enoxaparin for thromboprophylaxis after total knee arthroplasty: the STARS E3 trial," Thrombosis Research, vol. 134, no. 6, pp. 1198-1204, 2014.

[33] G. Raskob, A. T. Cohen, B. I. Eriksson et al., "Oral direct factor Xa inhibition with edoxaban for thromboprophylaxis after elective total hip replacement," Thrombosis and Haemostasis, vol. 104, no. 3, pp. 642-649, 2010.

[34] S. Rohatagi, J. Mendell, H. Kastrissios et al., "Characterisation of exposure versus response of edoxaban in patients undergoing total hip replacement surgery," Thrombosis and Haemostasis, vol. 108, no. 5, pp. 887-895, 2012.

[35] T. Fuji, S. Fujita, S. Tachibana et al., "Efficacy and safety of edoxaban versus enoxaparin for the prevention of venous thromboembolism following total hip arthroplasty: STARS J-V trial," in Proceedings of the 52nd Annual Meeting of the American Society of Hematology, p. 3320, Orlando, Fla, USA, December 2010.

[36] T. Fuji, S. Fujita, Y. Kawai et al., "Safety and efficacy of edoxaban in patients undergoing hip fracture surgery," Thrombosis Research, vol. 133, no. 6, pp. 1016-1022, 2014.

[37] The Hokusai-VTE Investigators, "Edoxaban versus warfarin for the treatment of symptomatic venous thromboembolism," The New England Journal of Medicine, vol. 369, pp. 1406-1415, 2013.
[38] R. P. Giugliano, C. T. Ruff, E. Braunwald et al., "Edoxaban versus warfarin in patients with atrial fibrillation," The New England Journal of Medicine, vol. 369, no. 22, pp. 2093-2104, 2013.

[39] R. N. H. Pugh, I. M. Murray-Lyon, and J. L. Dawson, “Transection of the oesophagus for bleeding oesophageal varices," British Journal of Surgery, vol. 60, no. 8, pp. 646-649, 1973.

[40] J. Graff and S. Harder, "Anticoagulant therapy with the oral direct factor Xa inhibitors rivaroxaban, apixaban and edoxaban and the thrombin inhibitor dabigatran etexilate in patients with hepatic impairment," Clinical Pharmacokinetics, vol. 52, no. 4, pp. 243-254, 2013.

[41] W. E. Dager and T. H. Kiser, "Systemic anticoagulation considerations in chronic kidney disease," Advances in Chronic Kidney Disease, vol. 17, no. 5, pp. 420-427, 2010.

[42] H. Heidbuchel, P. Verhamme, M. Alings et al., "European Heart Rhythm Association Practical Guide on the use of new oral anticoagulants in patients with non-valvular atrial fibrillation," Europace, vol. 15, no. 5, pp. 625-651, 2013.

[43] Y. Koretsune, T. Yamashita, and M. Yasaka, "Evaluation of edoxaban in patients with atrial fibrillation and severe renal impairment," European Heart Journal, vol. 34, supplement 1, 2013.

[44] D. A. Parasrampuria, T. Marbury, N. Matsushima et al., "Pharmacokinetics, safety, and tolerability of edoxaban in end-stage renal disease subjects undergoing haemodialysis," Thrombosis and Haemostasis, vol. 113, no. 4, pp. 719-727, 2015.

[45] P. B. Nielsen, D. A. Lane, L. H. Rasmussen, G. Y. H. Lip, and T. B. Larsen, "Renal function and non-vitamin K oral anticoagulants in comparison with warfarin on safety and efficacy outcomes in atrial fibrillation patients: a systemic review and metaregression analysis," Clinical Research in Cardiology, vol. 104, no. 5, pp. 418-429, 2015.

[46] T. Fuji, S. Fujita, Y. Kawai et al., "A randomized, open-label trial of edoxaban in Japanese patients with severe renal impairment undergoing lower-limb orthopedic surgery," Thrombosis Journal, vol. 13, article 6, 2015.

[47] H. Kawaji, M. Ishii, Y. Tamaki, K. Sasaki, and M. Takagi, "Edoxaban for prevention of venous thromboembolism after major orthopedic surgery," Orthopedic Research and Reviews, vol. 4, pp. 53-64, 2012.

[48] P. Kinov, P. P. Tanchev, M. Ellis, and G. Volpin, "Antithrombotic prophylaxis in major orthopaedic surgery: an historical overview and update of current recommendations," International Orthopaedics, vol. 38, no. 1, pp. 169-175, 2014.

[49] Y. Falck-Ytter, C. W. Francis, N. A. Johanson et al., "Prevention of VTE in orthopedic surgery patients: Antithrombotic Therapy and Prevention of Thrombosis, 9th ed: American College of Chest Physicians Evidence-Based Clinical Practice Guidelines," Chest, vol. 141, supplement 2, pp. e278S-e325S, 2012.

[50] T. Fuji, S. Fujita, S. Tachibana, and Y. Kawai, "A dose-ranging study evaluating the oral factor Xa inhibitor edoxaban for the prevention of venous thromboembolism in patients undergoing total knee arthroplasty," Journal of Thrombosis and Haemostasis, vol. 8, no. 11, pp. 2458-2468, 2010.

[51] H. Sasaki, K. Ishida, N. Shibanuma et al., "Retrospective comparison of three thromboprophylaxis agents, edoxaban, fondaparinux, and enoxaparin, for preventing venous thromboembolism in total knee arthroplasty," International Orthopaedics, vol. 38, no. 3, pp. 525-529, 2014.

[52] T. Fuji, C. J. Wang, S. Fujita, Y. Kawai, T. Kimura, and S. Tachibana, "Safety and efficacy of edoxaban, an oral factor Xa 
inhibitor, for thromboprophylaxis after total hip arthroplasty in Japan and Taiwan," The Journal of Arthroplasty, vol. 29, no. 12, pp. 2439-2436, 2014.

[53] A. C. Spyropoulos, F. A. Anderson Jr., G. FitzGerald et al., "Predictive and associative models to identify hospitalized medical patients at risk for VTE," Chest, vol. 140, no. 3, pp. 706714, 2011.

[54] M. M. Samama, A. T. Cohen, J.-Y. Darmon et al., "A comparison of enoxaparin with placebo for the prevention of venous thromboembolism in acutely ill medical patients," The New England Journal of Medicine, vol. 341, no. 11, pp. 793-800, 1999.

[55] A. Leizorovicz, A. T. Cohen, A. G. G. Turpie, C.-G. Olsson, P. T. Vaitkus, and S. Z. Goldhaber, "Randomized, placebocontrolled trial of dalteparin for the prevention of venous thromboembolism in acutely ill medical patients," Circulation, vol. 110, no. 7, pp. 874-879, 2004.

[56] A. T. Cohen, B. L. Davidson, A. S. Gallus et al., "Efficacy and safety of fondaparinux for the prevention of venous thromboembolism in older acute medical patients: randomised placebo controlled trial," British Medical Journal, vol. 332, no. 7537, pp. 325-329, 2006.

[57] V. F. Tapson, H. Decousus, M. Pini et al., "Venous thromboembolism prophylaxis in acutely ill hospitalized medical patients: findings from the international medical prevention registry on venous thromboembolism," Chest, vol. 132, no. 3, pp. 936-945, 2007.

[58] C. Kearon, E. A. Akl, A. J. Comerota et al., "Antithrombotic therapy for VTE disease: antithrombotic therapy and prevention of thrombosis, 9th ed: American College of Chest Physicians evidence-based clinical practice guidelines," Chest, vol. 141, supplement 2, pp. e419S-e494S, 2012.

[59] S. Z. Goldhaber, A. Leizorovicz, A. K. Kakkar et al., "Apixaban versus enoxaparin for thromboprophylaxis in medically ill patients," The New England Journal of Medicine, vol. 365, no. 23, pp. 2167-2177, 2011.

[60] A. T. Cohen, T. E. Spiro, H. R. Buller et al., "Rivaroxaban for thromboprophylaxis in acutely ill medical patients," The New England Journal of Medicine, vol. 368, pp. 513-523, 2013.

[61] M. G. Beckman, W. C. Hooper, S. E. Critchley, and T. L. Ortel, "Venous thromboembolism a public health concern," American Journal of Preventive Medicine, vol. 38, no. 4, pp. S495-S501, 2010.

[62] C. Kearon, E. A. Akl, A. J. Comerota et al., "Antithrombotic therapy for VTE disease: antithrombotic therapy and prevention of thrombosis, 9th ed: American College of Chest Physicians evidence-based clinical practice guidelines," Chest, vol. 141, no. 2, supplement, pp. e419S-e494S, 2012.

[63] R. Bauersachs, S. D. Berkowitz, B. Brenner et al., "Oral rivaroxaban for symptomatic venous thromboembolism," The New England Journal of Medicine, vol. 363, no. 26, pp. 2499-2510, 2010.

[64] H. R. Büller, M. Prins, A. W. A. Lensing et al., "Oral rivaroxaban for the treatment of symptomatic pulmonary embolism," The New England Journal of Medicine, vol. 366, no. 14, pp. 1287-1297, 2012.

[65] G. Agnelli, H. R. Buller, A. Cohen et al., "Oral apixaban for the treatment of acute venous thromboembolism," The New England Journal of Medicine, vol. 369, no. 9, pp. 799-808, 2013.

[66] P. Prandoni, F. Noventa, A. Ghirarduzzi et al., "The risk of recurrent venous thromboembolism after discontinuing anticoagulation in patients with acute proximal deep vein thrombosis or pulmonary embolism. A prospective cohort study in 1,626 patients," Haematologica, vol. 92, no. 2, pp. 199-205, 2007.

[67] M. Carrier, G. Le Gal, P. S. Wells, and M. A. Rodger, "Systematic review: case-fatality rates of recurrent venous thromboembolism and major bleeding events among patients treated for venous thromboembolism," Annals of Internal Medicine, vol. 152, no. 9, pp. 578-589, 2010.

[68] G. Agnelli, H. R. Buller, A. Cohen et al., "Apixaban for extended treatment of venous thromboembolism," The New England Journal of Medicine, vol. 368, no. 8, pp. 699-708, 2013.

[69] R. Bauersachs, S. D. Berkowitz, B. Brenner et al., "Oral rivaroxaban for symptomatic venous thromboembolism," The New England Journal of Medicine, vol. 363, pp. 2499-2510, 2010.

[70] A. Varki, “Trousseau's syndrome: multiple definitions and multiple mechanisms," Blood, vol. 110, no. 6, pp. 1723-1729, 2007.

[71] T. Wun and R. H. White, "Venous thromboembolism (VTE) in patients with cancer: epidemiology and risk factors," Cancer Investigation, vol. 27, no. 1, pp. 63-74, 2009.

[72] C. E. Chee, A. A. Ashrani, R. S. Marks et al., "Predictors of venous thromboembolism recurrence and bleeding among active cancer patients: a population-based cohort study," Blood, vol. 123, no. 25, pp. 3972-3978, 2014.

[73] J. Trujillo-Santos, J. A. Nieto, G. Tiberio et al., "Predicting recurrences or major bleeding in cancer patients with venous thromboembolism: findings from the RIETE registry," Thrombosis \& Haemostasis, vol. 100, no. 3, pp. 435-439, 2008.

[74] A. Khorana, N. M. Kuderer, E. Culakova, G. H. Lyman, and C. W. Francis, "Development and validation of a predictive model for chemotherapy- associated thrombosis," Blood, vol. 111, no. 10, pp. 4902-4907, 2008.

[75] M. N. Levine, C. Gu, H. A. Liebman et al., "A randomized phase II trial of apixaban for the prevention of thromboembolism in patients with metastatic cancer," Journal of Thrombosis and Haemostasis, vol. 10, no. 5, pp. 807-814, 2012.

[76] M. H. Prins, A. W. A. Lensing, T. A. Brighton et al., "Oral rivaroxaban versus enoxaparin with vitamin $\mathrm{K}$ antagonist for the treatment of symptomatic venous thromboembolism in patients with cancer (EINSTEIN-DVT and EINSTEIN-PE): a pooled subgroup analysis of two randomised controlled trials," The Lancet Haematology, vol. 1, no. 1, pp. e37-e46, 2014.

[77] T. B. Larsen, P. B. Nielsen, F. Skøjoth et al., "Non-vitamin K antagonist oral anticoagulants and the treatment of venous thromboembolism in cancer patients: a systemic review and meta-analysis of safety and efficacy outcomes," PLoS ONE, vol. 9, no. 12, Article ID el14445, 2014.

[78] M. C. Vedovati, F. Germini, G. Agnelli, and C. Becattini, "Direct oral anticoagulants in patients With VTE and cancer," Chest Journal, vol. 147, no. 2, pp. 475-483, 2015.

[79] NCCN, April 2015, http://www.nccn.org/professionals/physician_gls/pdf/vte.pdf.

[80] G. H. Lyman, K. Bohlke, A. A. Khorana et al., "Venous thromboembolism prophylaxis and treatment in patients with cancer: American society of clinical oncology clinical practice guideline update 2014," Journal of Clinical Oncology, vol. 33, no. 6, pp. 654-656, 2015.

[81] J. L. Mega, E. Braunwald, S. D. Wiviott et al., "Rivaroxaban in patients with a recent acute coronary syndrome," The New England Journal of Medicine, vol. 366, no. 1, pp. 9-19, 2012.

[82] J. H. Alexander, R. D. Lopes, S. James et al., "Apixaban with antiplatelet therapy after acute coronary syndrome," The New England Journal of Medicine, vol. 365, no. 8, pp. 699-708, 2011. 
[83] E. C. Jauch, J. L. Saver, H. P. Adams et al., "Guidelines for the early management of patients with acute ischemic stroke: a guideline for healthcare professionals from the American Heart Association/American Stroke Association," Stroke, vol. 44, no. 3, pp. 870-947, 2013.

[84] M. U. Zafar, D. A. Vorchheimer, J. Gaztanaga et al., "Antithrombotic effects of factor Xa inhibition with DU-176b: phase-I study of an oral, direct factor Xa inhibitor using an ex-vivo flow chamber," Thrombosis and Haemostasis, vol. 98, no. 4, pp. 883888, 2007.

[85] J. I. Weitz, S. J. Connolly, I. Patel et al., "Randomised, parallelgroup, multicentre, multinational phase 2 study comparing edoxaban, an oral factor Xa inhibitor, with warfarin for stroke prevention in patients with atrial fibrillation," Thrombosis and Haemostasis, vol. 104, no. 3, pp. 633-641, 2010.

[86] Y. Morishima and C. Kamisato, "Laboratory measurements of the oral direct factor xa inhibitor edoxaban: comparison of prothrombin time, activated partial thromboplastin time, and thrombin generation assay," The American Journal of Clinical Pathology, vol. 143, no. 2, pp. 241-247, 2015.

[87] T. Fukuda, Y. Honda, C. Kamisato, Y. Morishima, and T. Shibano, "Reversal of anticoagulant effects of edoxaban, an oral, direct factor Xa inhibitor, with haemostatic agents," Thrombosis and Haemostasis, vol. 107, no. 2, pp. 253-259, 2012.

[88] E. Herzog, F. Kaspereit, W. Krege et al., "Effective reversal of edoxaban-associated bleeding with four-factor prothrombin complex concentrate in a rabbit model of acute hemorrhage," Anesthesiology, vol. 122, no. 2, pp. 387-398, 2015.

[89] A.-B. Halim, M. M. Samama, and J. Mendell, "Ex vivo reversal of the anticoagulant effects of edoxaban," Thrombosis Research, vol. 134, no. 4, pp. 909-913, 2014.

[90] S. Kaatz, P. A. Kouides, D. A. Garcia et al., "Guidance on the emergent reversal of oral thrombin and factor Xa inhibitors," American Journal of Hematology, vol. 87, no. 1, pp. S141-S145, 2012.

[91] L. M. Baumann Kreuziger, J. C. Keenan, C. Morton, and D. J. Dries, "Management of bleeding patient receiving new oral anticoagulants: a role for thrombin complex concentrates," BioMed Research International, vol. 2014, Article ID 583794, 7 pages, 2014.

[92] H. Zahir, K. S. Brown, A. G. Vandell et al., "Edoxaban effects on bleeding following punch biopsy and reversal by a 4-FPCC prothrombin complex concentrate," Circulation, vol. 131, pp. 8290, 2015.

[93] Y. Mo and F. K. Yam, "Recent advances in the development of specific antidotes for target-specific oral anticoagulants," Pharmacotherapy, vol. 35, no. 2, pp. 198-207, 2015.

[94] J. W. Eikelboom, M. Brueckmann, F. van de Werf et al., "Dabigatran versus warfarin in patients with mechanical heart valves," The New England Journal of Medicine, vol. 369, no. 13, pp. 1206-1214, 2013.

[95] M. H. Prins, L. Bamber, S. J. Cano et al., "Patient-reported treatment satisfaction with oral rivaroxaban versus standard therapy in the treatment of pulmonary embolism: results from the EINSTEIN-PE trial," Thrombosis Research, vol. 135, no. 2, pp. 281-288, 2015.

[96] L. Bamber, M. Y. Wang, M. H. Prins et al., "Patient-reported treatment satisfaction with oral rivaroxaban versus standard therapy in the treatment of acute symptomatic deep-vein thrombosis," Thrombosis and Haemostasis, vol. 110, no. 4, pp. 732-741, 2013.
[97] M. Mahmoudi and D. M. Sobieraj, “The cost-effectiveness of oral direct factor Xa inhibitors compared with low-molecularweight heparin for the prevention of venous thromboembolism prophylaxis in total hip or knee replacement surgery," Pharmacotherapy, vol. 33, no. 12, pp. 1333-1340, 2013.

[98] A. Amin, A. Bruno, J. Trocio, J. Lin, and M. Lingohr-Smith, "Comparison of differences in medical costs when new oral anticoagulants are used for the treatment of patients with nonvalvular atrial fibrillation and venous thromboembolism vs warfarin or placebo in the US," Journal of Medical Economics, vol. 18, no. 6, pp. 399-409, 2015. 


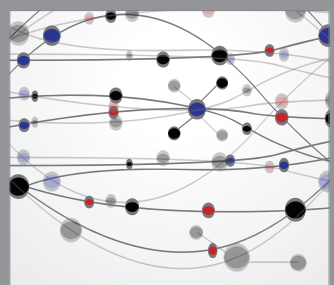

The Scientific World Journal
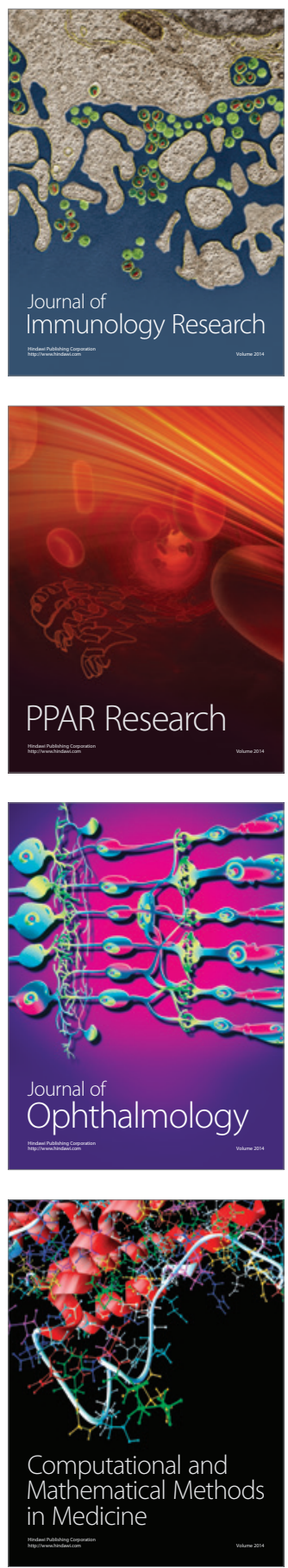

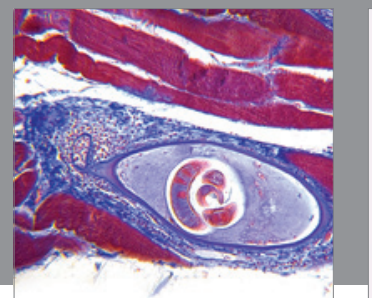

Gastroenterology

Research and Practice
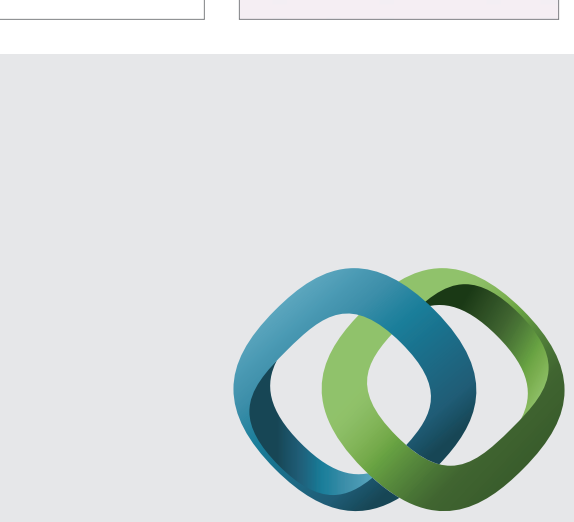

\section{Hindawi}

Submit your manuscripts at

http://www.hindawi.com
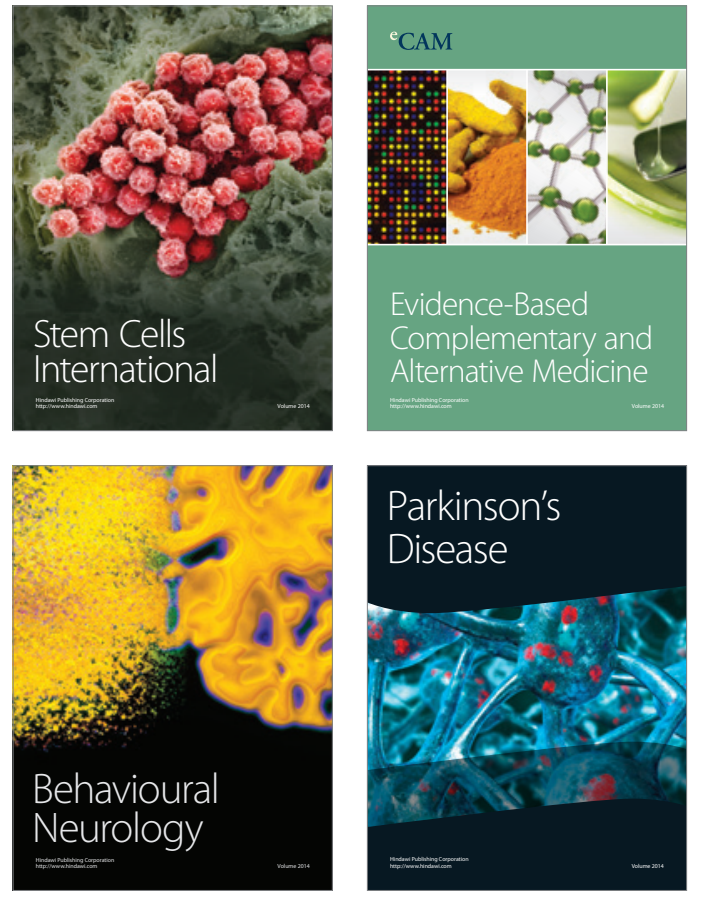
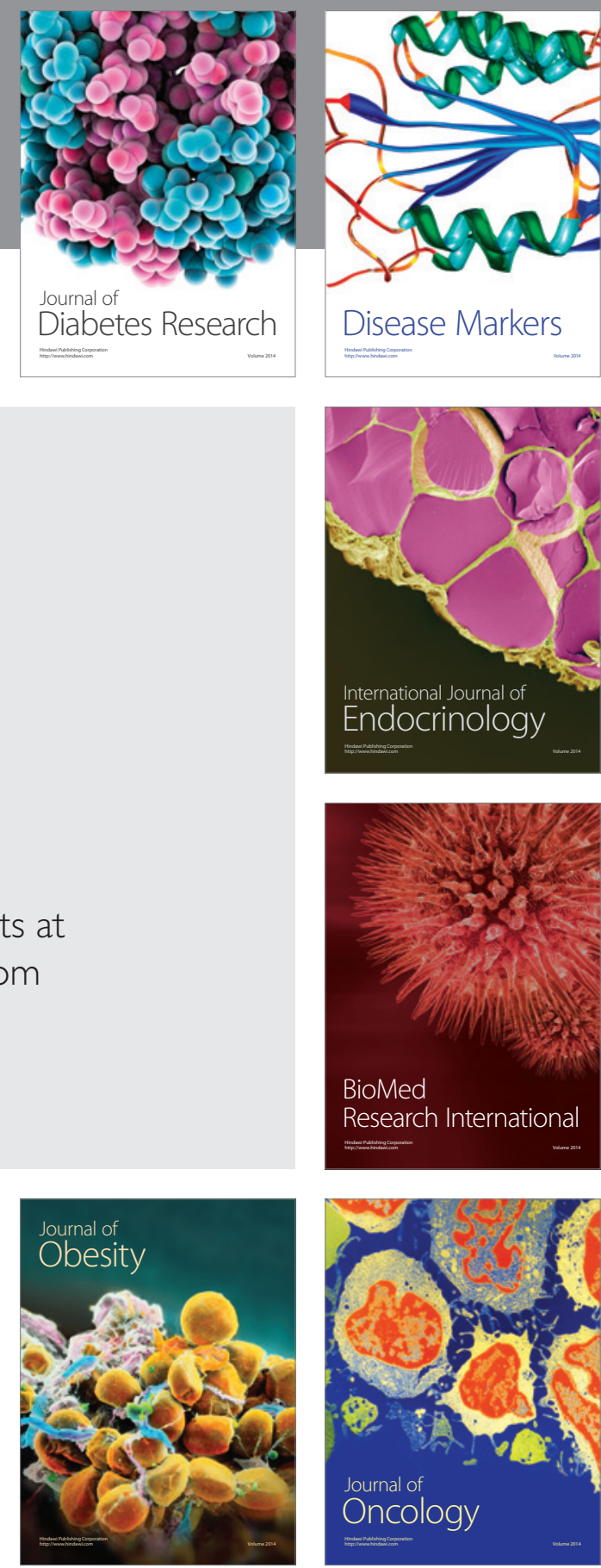

Disease Markers
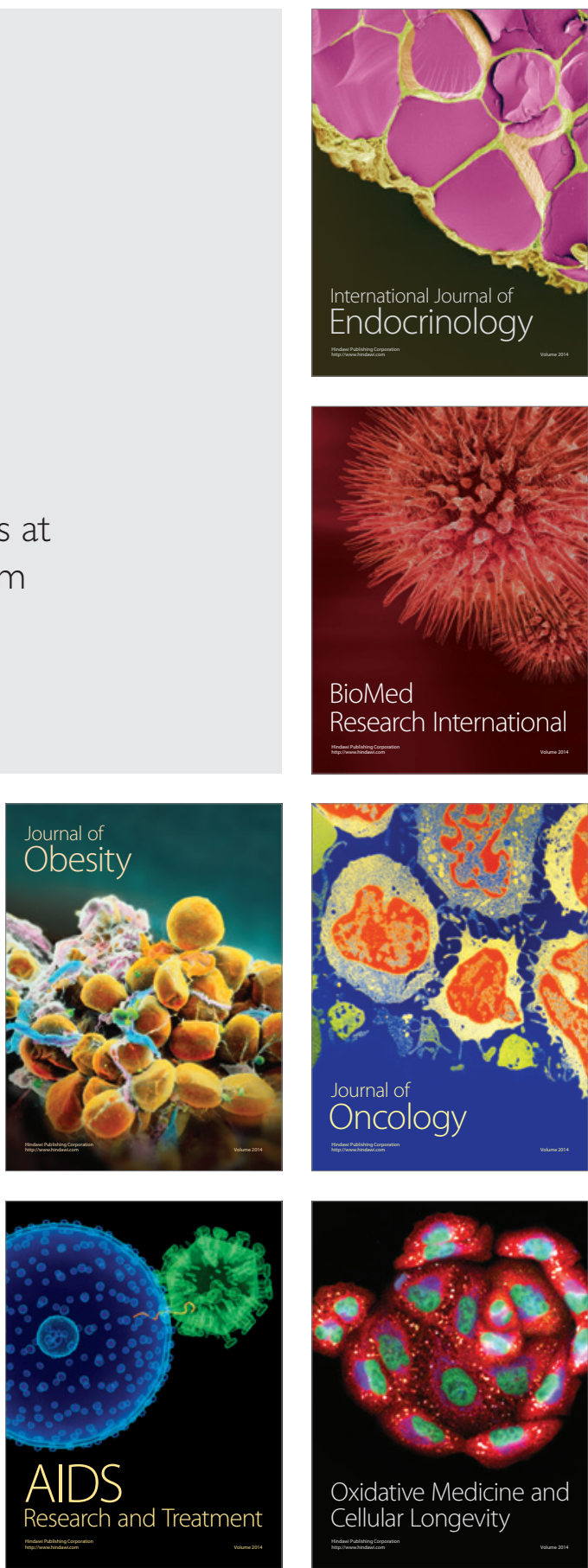